\title{
ANÁLISIS LINGÜÍSTICO Y FILOSÓFICO EN DEFINICIONES DE ALFIN APLICANDO TÉCNICAS BIBLIOMÉTRICAS
}

\author{
Liuris Rodríguez Castilla* \\ Instituto Superior Politécnico "José Antonio Echeverría" CUJAE. Ciudad de La Habana. \\ Alejandro Uribe Tirado ${ }^{* *}$ \\ Universidad de Antioquia. Colombia. \\ Juan Francisco Cabrera Ramos ${ }^{* * *}$ \\ Instituto Superior Politécnico "José Antonio Echeverría" CUJAE. Ciudad de La Habana. \\ Rolando Serra Toledo ${ }^{* * * *}$ \\ Instituto Superior Politécnico "José Antonio Echeverría" CUJAE. Ciudad de La Habana.
}

\begin{abstract}
Resumen: La investigación expone un análisis lingüístico y filosófico de diversas definiciones de ALFIN para identificar los elementos que las conforman y cuántas de ellas incluyen la mayor cantidad de atributos que permitan seleccionarlas como las más completas desde un enfoque científico. La investigación toma como muestra 52 definiciones sobre el tema de alfabetización informacional, y aplica técnicas bibliométricas para realizar un análisis general sobre las definiciones y reflejarlas en mapas de visualización. La investigación toma como punto de partida dos artículos publicados por los autores Bawden y Uribe que realizan un análisis en definiciones de ALFIN. El artículo aporta a la comunidad investigativa un análisis exhaustivo de las definiciones relacionadas con la temática ALFIN hasta el año 2012, agrupándolas cronológicamente y ofreciendo datos de valor agregado con respecto a la autoría de cada definición.

Palabras clave: definiciones de ALFIN; análisis bibliométrico; análisis lingüístico de ALFIN; análisis de conceptos.

Title: LINGUISTIC AND PHILOSOPHICAL ANALYSIS IN DEFINITION ALFIN APPLYING BIBLIOMETRIC TECHNIQUES.

Abstract: Research presents a linguistic and philosophical analysis in various definitions of information literacy to identify the elements that make up and how many of them include as many attributes that allow select as the most complete from a scientific approach. Research shows 52 takes as definitions about information literacy, and applies bibliometric techniques for general analysis of the definitions and reflects on maps display. The article gives the research community a comprehensive analysis of related definitions information literacy theme until 2012, grouped chronologically and offering value-added data regarding the authorship of each definition.

Keywords: definitions of information literacy; bibliometric analysis; linguistic analysis of ALFIN.
\end{abstract}

\section{INTRODUCCIÓN}

El desarrollo de las tecnologías computacionales y de la informática, así como el acceso a la información a través de redes e internet, son algunos de los medios cada vez más usados en la educación superior por estudiantes y profesores. Esto ha dado lugar a la introducción de nuevas materias en la enseñanza: la Alfabetización Informacional (ALFIN), que impulsa el desarrollo de habilidades para el uso adecuado de la información, disponible en grandes volúmenes a través de estos medios tecnológicos antes mencionados.

Esta disciplina ha sido aplicada en el sector educativo y de investigación de disímiles países, dentro de los que cabe destacar Estados Unidos, Gran Bretaña, Australia, Canadá y los países nórdicos. A nivel Iberoamericano en España, Brasil, México, Cuba, Colombia, entre otros. Es apoyada y aplicada por varias organizaciones como la (UNESCO, ALA, IFLA, ALFINCAT, ACRL, ANZIIL, FUNDACIÓN GABRIEL PIEDRAHITA) y muchas otras. En la actualidad, la temática cuenta con una red de colaboradores en el mundo que desarrollan programas, modelos, normas y estándares aplicados a sus sistemas educacionales para la instrucción de estos nuevos conocimientos.

\footnotetext{
*1iuris@crea.cujae.edu.cu, liurisz@gmail.com

** auribe.bibliotecologia.udea@gmail.com, auribe@correo.ugr.es

*** jcabrera@crea.cujae.edu.cu

****sserratoledo@gmail.com, serra@electrica.cujae.edu.cu
}

Recibido: 28-06-2016; 2 $2^{\mathrm{a}}$ versión: 19-07-2016; 3ª versión: 10-08-2016; aceptado: 19-09-2016.

RODRÍGUEZ CASTILLA, L.; URIBE TIRADO, A.; CABRERA RAMOS, J.F. y SERRA TOLEDO, R. Análisis lingüístico y filosófico en definiciones de ALFIN aplicando técnicas bibliométricas. Anales de Documentación, 2016, vol. 19, $\mathrm{n}^{\circ} 2$. Disponible en: http://dx.doi.org/10.6018/analesdoc.19.2.262431. 
La producción científica sobre la disciplina es muy amplia y con ella la variedad de definiciones dadas por diversos autores. Uno de los problemas que con frecuencia nos enfrentamos los investigadores, es en la selección de la(s) definiciones más adecuadas a nuestra investigación y asumir a partir de ella una posición autoral o aportar un nuevo concepto sobre el tema. Para ello es importante conocer los elementos que debe contener una definición y cómo debe estar estructurada.

Este artículo toma como punto de partida dos antecedentes que publicaran los autores David Bawden y Uribe Tirado en las revistas Anales de Documentación y Acimed respectivamente. Donde realizan análisis de definiciones de ALFIN desde diversas perspectivas.

El primero, David Bawden (Bawden, 2002), describe y revisa conceptos de Alfabetización Informacional (AI) y alfabetización digital con otros conceptos relacionados, como el de alfabetización informática, la alfabetización bibliotecaria, la alfabetización en redes, la de internet y la hiper-alfabetización, y se aclaran las relaciones entre éstas. Concluye con la exposición de conceptos generales, como son AI y alfabetización digital, que estando basadas en conocimiento, percepciones y actitudes, se apoyan en las alfabetizaciones basadas en destrezas más simples.

El segundo, Uribe Tirado (Uribe Tirado, 2009), interrelaciona veinte definiciones de alfabetización informacional y propone una macro-definición a partir del análisis de las más utilizadas en las últimas dos décadas. Para ello emplea técnicas discursivas, algunas de análisis de dominio, y especialmente de análisis estadístico, de redes y de representación de información, con el objetivo de identificar tendencias e interrelaciones entre los términos utilizados en ellas y sus autores, las implicaciones teóricas y prácticas de esas tendencias y el uso de ciertos términos.

Con respecto a las investigaciones precedentes se incorporan 28 nuevas definiciones (ver Anexo) y se toman con especial interés las aportadas por instituciones de respaldo internacional (ALA, UNESCO, IFLA). Se organizan cronológicamente (ver Anexo) y se describen datos generales de los autores.

El objetivo de esta investigación y su principal aporte, radica en mostrar los resultados desde un análisis lingüístico y filosófico en estas definiciones de ALFIN, que permita a los investigadores seleccionar la(s) más completas desde un enfoque científico. Para ello se evalúan las características que deben cumplir lingüística y filosóficamente una definición y cuántas de ellas incluyen la mayor cantidad de atributos que permitan seleccionarlas como las más completas.

\section{MATERIALES Y MÉTODOS}

La investigación toma como muestra 52 definiciones sobre el tema de alfabetización informacional, publicadas hasta 2012. Se determinó cerrar la investigación hasta este año porque coincide con la Declaración de Moscú, documento que aborda ampliamente la temática sobre Alfabetización Mediática e Informacional y que además está respaldada por organizaciones internacionales de reconocido prestigio en la comunidad científica como la IFLA, UNESCO, IFAP y la ALA. Este documento fue aprobado también por una amplia representación de investigadores (130 participantes) de 40 países.

Se aplican técnicas bibliométricas para realizar un análisis general y reflejarlas en mapas de visualización. Entre los indicadores evaluados están: coincidencia de términos de denominación (cantidad de veces coincidentes); definiciones por años; categoría de autores (personales e institucionales); colaboración autoral; relación y coincidencia entre palabras claves descritas.

Se realiza conjuntamente una comparación semántica entre los conceptos, evaluando la coincidencia de los elementos que deben estar presentes en una definición (lingüísticos y filosóficos). Para ello se tomaron como indicadores: clase, género, atributos, referencia al término, tamaño, inclusión del término en el contenido, claridad y negatividad. Se tuvo en cuenta también, evaluaciones externas recibidas por otros investigadores.

Se utilizaron como herramientas, el gestor bibliográfico EndNote para la gestión de bibliografías, el conteo de atributos y la coincidencia semántica de los elementos presentes en las definiciones. Los softwares UCINET, Bibexel, y NetDraw para el análisis y visualización de los resultados. 


\section{RESULTADOS Y DISCUSIÓN}

\subsection{Evolución de la ALFIN. Denominaciones y etapas}

En la literatura sobre ALFIN variados son los términos utilizados para identificarla, algunos de los cuales tienen a su vez expresiones relacionadas que parecen usarse como sinónimos, dentro de los que pueden mencionarse:

- Alfabetización informacional / ALFIN / Information literacy.

- Alfabetización informática: sinónimos - alfabetización en nuevas tecnologías / alfabetización electrónica / alfabetización de información electrónica.

- Alfabetización bibliotecaria.

- Alfabetización en medios.

- Alfabetización de redes: sinónimos - alfabetización en internet, hiper-alfabetización.

- Alfabetización digital: sinónimo - alfabetización en información digital.

- Competencia(s) informacional(es) / competencia y fluidez informacional.

- Literacy skills = DHI (Desarrollo de Habilidades en Información).

- Habilidades informacionales.

- Cultura informacional.

- Desempeño informacional (literacy performance).

- Alfabetismo en información.

- Alfabetización informativa.

- Alfabetización en información.

- ALFIN 2.0.

- Competencias Digitales (Digcomp - Digcom 2.0) (Ferrari, 2013); (Joint Research Centre, 2016).

- Competencias informáticas e informacionales (Cl2 - UniCl 2) (Universidad de Sevilla, 2016); (Red de bibliotecas universitarias, 2012).

En los últimos años han ido ganando posicionamiento otros términos (Mackey y Jacobson, 2014) que incluyen la ALFIN en interrelación con otras alfabetizaciones, los cuales van marcando la tendencia predominante en la comunidad científica, dentro de las que pueden mencionarse:

- Multiliteracy

- Metaliteracy

La ALFIN ha sido además, desarrollada y aplicada desde múltiples aristas como las de bibliotecas públicas, escolares, especializadas y universitarias; en espacios educativos escolares y universitarios; en el medio empresarial y organizacional. A su vez se vincula desde entornos culturales, educativos, mediáticos, computacionales, tecnológicos, laborales, políticos y muchos otros. Su evolución ha sido reflejada en diversos estudios por autores como (Bawden, 2002); (Pinto Molina et al., 2010); (Uribe Tirado et al., 2011), donde el punto coincidente ha sido el reconocimiento de la información como un recurso necesario para el desarrollo de las sociedades contemporáneas.

Entre la diversidad de criterios sobre esta disciplina, se identificaron 52 definiciones, para el análisis de la investigación, ofrecidas por 57 autores, de los cuales 44 son personales y 13 institucionales. Se identifican también algunos datos referenciales sobre los autores que definen el término (ver Anexo).

\subsection{Análisis de las definiciones}

A partir de estas definiciones (ver Anexo), primero se realizó un análisis con la coincidencia de términos con la que se denominaban, resultando como más difundido el nombre de ALFIN que representa la sigla de alfabetización informacional, segundo nombre más utilizado por los autores con un total de 15 y 11 coincidencias respectivamente.

Se analizó también la cantidad de definiciones por años y las mayores producciones se muestran en los años 2002, 2003 y 2011 con 5 publicaciones cada uno, coincidiendo con eventos científicos de relevancia en la temática como los congresos de la IFLA y los acuerdos tomados en declaraciones internacionales y colectivas como Praga, Alejandría y Moscú.

Al mismo tiempo se analizaron otros indicadores con respecto a la autoría: personales o colectivos; nacionales e internacionales (con respecto a Cuba); especialidad; relación de colaboración entre ellos. De un total de 52 definiciones, 5 eran de autores cubanos y 47 extranjeros. De autorías personales estaban representadas 35, colectivas 9 e institucionales 8. Con respecto a la especialidad de formación, 9 de los autores se relacionan con las Ciencias de la 
Educación, 5 son de otras especialidades (medicina, empresariales) y resaltan 38 autores de las Ciencias de la Información (Figura 1).

Esto les da una fortaleza a las definiciones, primero porque es trabajada en todo el mundo desde diversas aristas, con énfasis en el desarrollo de habilidades y competencias desde la educación; y segundo, por el respaldo internacional que tiene desde las ciencias de la información, especialidad que se ocupa de estudiar el ciclo de vida de la información, principal componente de estas definiciones.

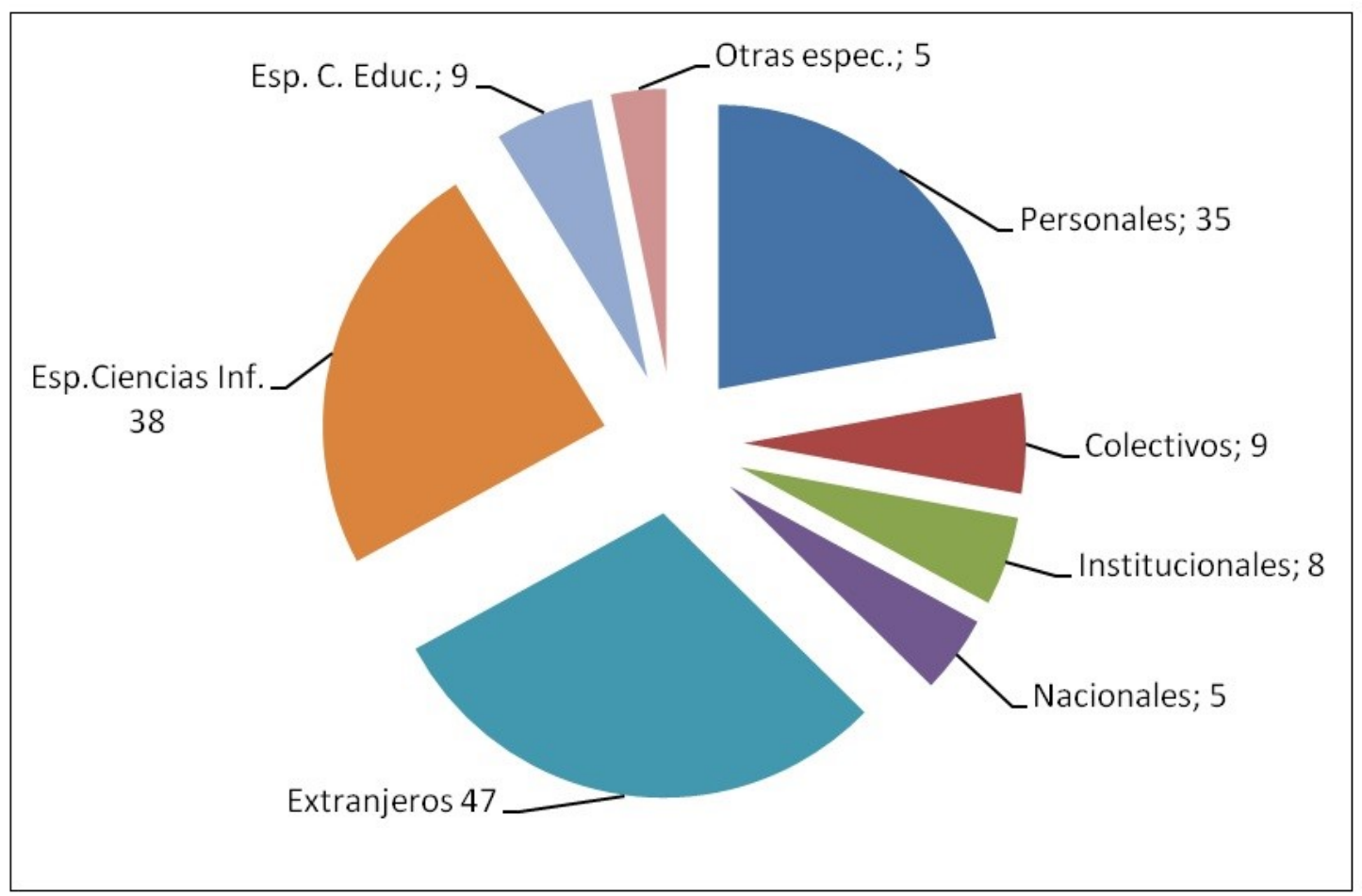

Figura 1. Definiciones por tipología de autores.

Al observar la relación entre los autores de estas definiciones, se destacan las colaboraciones institucionales, con tres nodos colectivos lideradas por la UNESCO junto a organizaciones que agrupan a especialistas de las ciencias de la información en el mundo como la IFLA (Figura 2). Este elemento también constituye una fortaleza para las definiciones pues tienen un respaldo internacional por instituciones reconocidas y de prestigio, y un amplio consenso por la comunidad científica que investiga en la temática. 


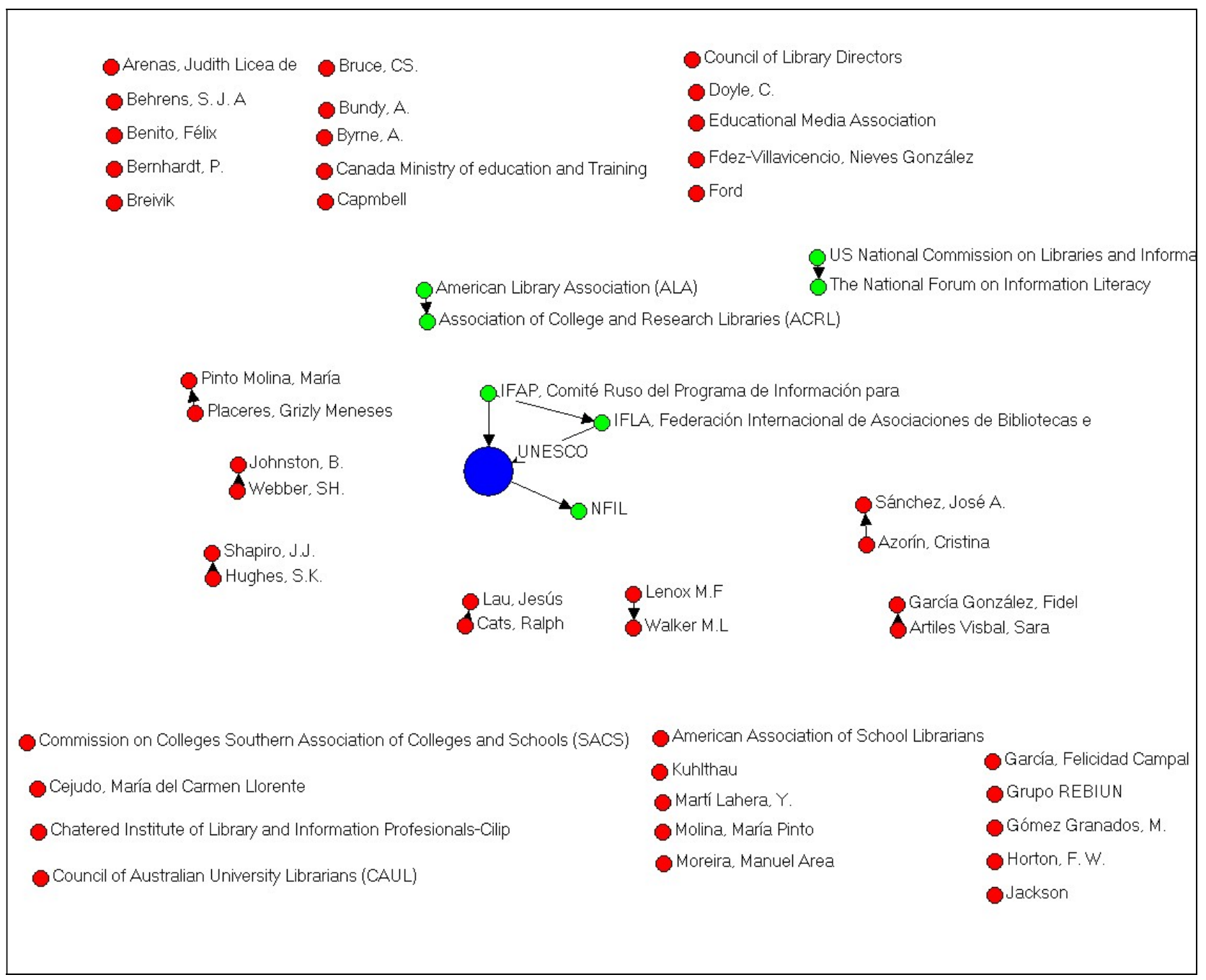

Figura 2. Colaboración entre autores.

También fueron analizadas las palabras clave que formaban las definiciones, encontrando como término común "información" presente en todos los enunciados, lo cual indica que todas están describiendo habilidades o competencias de tipo informacional. En otro orden de importancia se destacan con más de 20 coincidencias las especificaciones que se deben cumplir para las habilidades informacionales, establecidas y aprobadas por las organizaciones antes mencionadas como son: el uso eficiente de la información (26), la evaluación (25), el desarrollo de habilidades (23), la vinculación con las TIC (22) y la identificación de necesidades de información (21).

Al relacionar todas estas palabras clave, se observan un conjunto de nodos donde sigue predominando como término principal "información" resaltado en color azul (Figura 3) y en colores verdes otros nodos importantes que representan la coincidencia de ellos en las definiciones y su vinculación con la palabra principal (fuentes de información, TIC, conocimiento, evaluar, buscar, seleccionar, localizar, comunicar, necesidades, entre otras). A su vez, estos nodos verdes se relacionan con otros términos presentes también en las definiciones, pero en menor coincidencia, representados con colores rojos. 


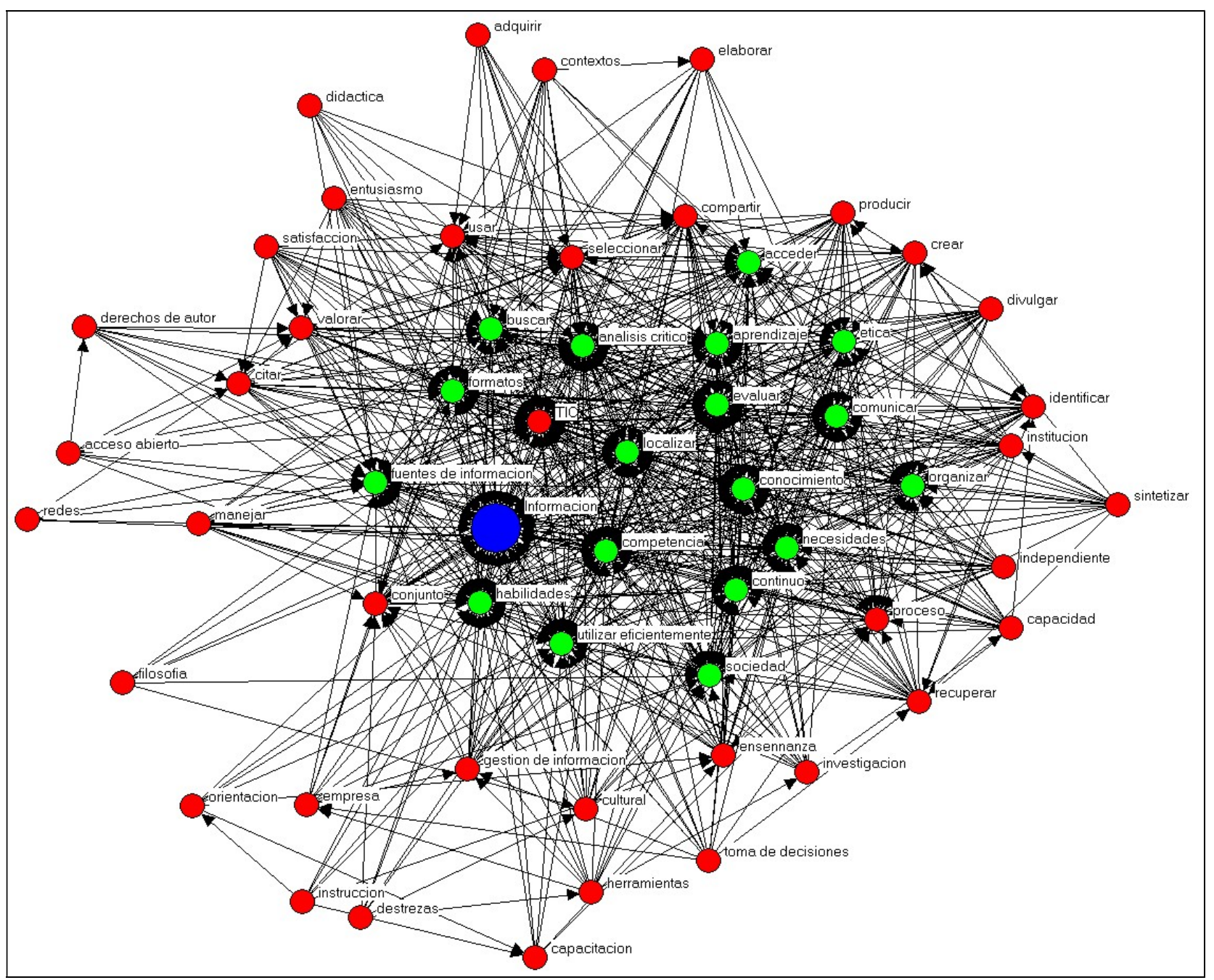

Figura 3. Relación entre palabras clave.

\subsection{Elementos que conforman una definición}

Desde el punto de vista lingüístico (Moore y Widdowson, 1987) y filosófico (Shields y Zalta, 2009) una definición como norma general, debe incluir:

- El género: clase a la que pertenecen los objetos, ideas o seres vivientes designados mediante el término definido.

- Diferencia específica: características diferenciales de esa clase. Por ejemplo, en la definición de lápiz: instrumento de escritura formado por una barra de grafito envuelta en madera, la primera parte: instrumento de escritura [...] es el género, y la segunda: [...] formado por una barra de grafito envuelta en madera es la diferencia específica.

Las reglas principales para enunciar una definición son:

- Mayor aproximación posible a su tipificación (de género y especie).

- Diferenciación: describir las características que le sean inherentes.

Como reglas de la definición también deben:

- Responde a la pregunta ¿qué es?

- No debe estar expresada en un lenguaje oscuro o ambiguo.

- La palabra (término) que se define o alguna similar, no debe ser parte de la definición.

- No debe ser demasiado amplia ni demasiado estrecha.

- No debe ser negativa: debe decir lo que el término es y no lo que no es.

- Debe indicar los atributos esenciales. 
Se tomaron todas las declaraciones y se buscó cuántos elementos de los que debe tener una definición están presentes en ellas y con esto seleccionar la(s) más completa(s). Inicialmente se realizó una exploración más simple buscando las características principales y se observó que en 45 está presente el género, en 50 refieren el término que describen, en 49 se ofrecen especificaciones sobre el término y 38 incluían los tres elementos (Figura 4).

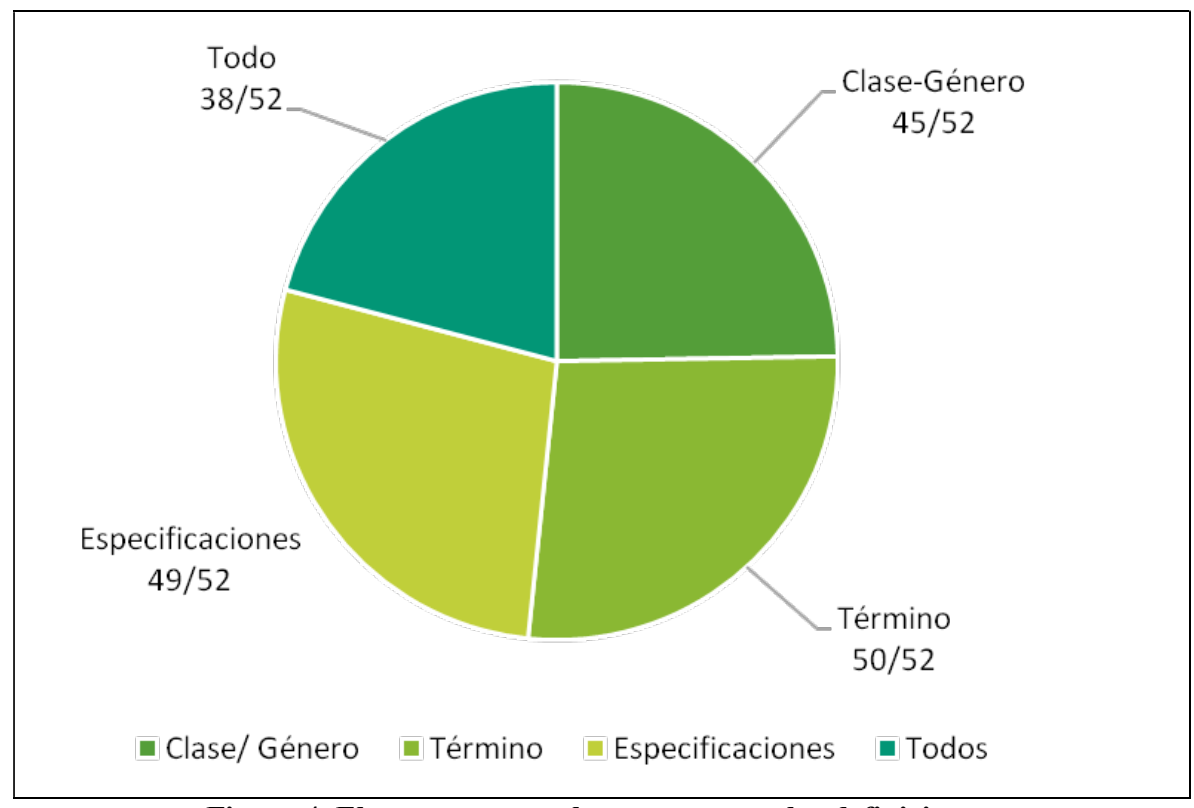

Figura 4. Elementos generales presentes en las definiciones.

Profundizando un poco más en las reglas que deben cumplir, se realizó una tabla comparativa con indicadores seleccionados según las características establecidas (Tabla I). Estos fueron:

1. Género: se busca si la definición se agrupa dentro de una clase.

2. Atributos: si describe elementos propios para ella.

3. Refiere al término: referencia en la descripción al término con el que se nombra.

4. Tamaño: si el tamaño no es excesivo o muy pequeño (en la columna tamaño las letras significan: A-adecuado, Ppequeño, G-grande).

5. Término incluido: si en la definición se utiliza el término con el que se nombra.

6. Claridad: si al leerlo se entiende con claridad lo que es.

7. Negatividad: Si dentro de la definición aparecen elementos negativos.

8. Valoración: si fue asumida por otros autores, se habían emitidos criterios de aceptación, o si había sido aprobada colectivamente por acuerdo.

\begin{tabular}{|c|c|c|c|c|c|c|c|c|}
\hline DEFINICIONES & $\begin{array}{cc}\overline{0} & 0 \\
\mathbb{\Xi} & : \\
\overline{0} & 0\end{array}$ & 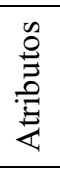 & 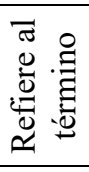 & 孞 & 导导 & 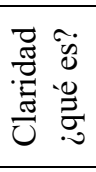 & 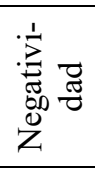 & 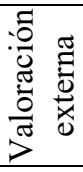 \\
\hline $\begin{array}{l}\text { 1. (Zurkowski, 1974) } \\
\text { Citado por (Campal García, 2011) }\end{array}$ & & $\mathrm{X}$ & $\mathrm{X}$ & A & $\mathrm{X}$ & $\mathrm{X}$ & & $\mathrm{X}$ \\
\hline $\begin{array}{l}\text { 2. (Owens, 1976) } \\
\text { Citado por (Campal García, 2011) }\end{array}$ & & $\mathrm{X}$ & $\mathrm{X}$ & A & $X$ & & & \\
\hline $\begin{array}{l}\text { 3. (Taylor, 1979) } \\
\text { Citado por (Campal García, 2011) }\end{array}$ & & $\mathrm{X}$ & $\mathrm{X}$ & A & & $\mathrm{X}$ & $\mathrm{X}$ & \\
\hline 4. (Woody Horton, 1983) & & & $X$ & $\mathrm{P}$ & $X$ & $\mathrm{X}$ & & \\
\hline $\begin{array}{l}\text { 5. (Kuhlthau, 1987) } \\
\text { Citado por (Uribe Tirado, 2009) }\end{array}$ & & $\mathrm{X}$ & $\mathrm{X}$ & A & $\mathrm{X}$ & $X$ & & \\
\hline
\end{tabular}




\begin{tabular}{|c|c|c|c|c|c|c|c|c|}
\hline DEFINICIONES & 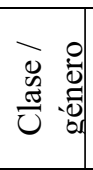 & $\begin{array}{c}\stackrel{0}{0} \\
\stackrel{0}{E} \\
\stackrel{E}{<}\end{array}$ & 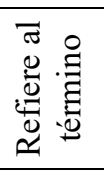 & 莺 & 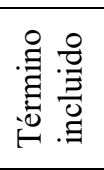 & 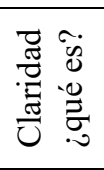 & 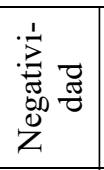 & 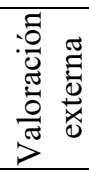 \\
\hline $\begin{array}{l}\text { 6. (ALA, 1989) } \\
\text { Citado por (Campal García, 2011) }\end{array}$ & & $X$ & X & A & $X$ & $X$ & & $X$ \\
\hline $\begin{array}{l}\text { 7. (Jackson, 1989) } \\
\text { Citado por (Uribe Tirado, 2009) }\end{array}$ & & $\mathrm{X}$ & X & $P$ & $\mathrm{X}$ & $\mathrm{X}$ & & \\
\hline 8. (Doyle, 1992) & & $\mathrm{X}$ & $\mathrm{X}$ & A & $\mathrm{X}$ & $\mathrm{X}$ & & \\
\hline $\begin{array}{l}\text { 9. (Lenox y Walker, 1993) } \\
\text { Citado por (Uribe Tirado, 2009) }\end{array}$ & & $X$ & X & A & X & X & & \\
\hline $\begin{array}{l}\text { 10. (Behrens, 1994) } \\
\text { Citado por (Campal García, 2011) }\end{array}$ & & $X$ & X & A & X & $X$ & & \\
\hline $\begin{array}{l}\text { 11. (Ford, 1994) } \\
\text { Citado por (Campal García, 2011) }\end{array}$ & & $X$ & X & A & X & $X$ & & \\
\hline $\begin{array}{l}\text { 12. (SACS, 1996) } \\
\text { Citado por (Ponjuán Dante, 2002) }\end{array}$ & & $X$ & X & A & $\mathrm{X}$ & $\mathrm{X}$ & & \\
\hline $\begin{array}{l}\text { 13. (Shapiro y Hughes, 1996) } \\
\text { Citado por (Uribe Tirado, 2009) }\end{array}$ & & $X$ & X & $\mathrm{P}$ & X & X & & \\
\hline $\begin{array}{l}\text { 14. (Council of Library Director, 1997) } \\
\text { Citado por (Ponjuán Dante, 2002) }\end{array}$ & $X$ & $X$ & X & $P$ & $X$ & $X$ & & $X$ \\
\hline $\begin{array}{l}\text { 15. (Bruce, 1997) } \\
\text { Citado por (Uribe Tirado, 2009) }\end{array}$ & $X$ & $X$ & $\mathrm{X}$ & A & & $\mathrm{X}$ & & \\
\hline $\begin{array}{l}\text { 16. (OCDE, 1998) } \\
\text { Citado por (Campal García, 2011) }\end{array}$ & $X$ & & X & $P$ & & & & $X$ \\
\hline $\begin{array}{l}\text { 17. (American Association of School } \\
\text { Librarians, 1998) }\end{array}$ & X & $X$ & X & A & $\mathrm{X}$ & $\mathrm{X}$ & & $\mathrm{X}$ \\
\hline $\begin{array}{l}\text { 18. (Ministry of Education Canada, } \\
\text { 1999) } \\
\text { Citado por (Campal García, 2011) }\end{array}$ & $\mathrm{X}$ & $X$ & $\mathrm{X}$ & $P$ & $\mathrm{X}$ & $\mathrm{X}$ & & \\
\hline $\begin{array}{l}\text { 19. (Bundy, 2000) } \\
\text { Citado por (Uribe Tirado, 2009) }\end{array}$ & X & $X$ & X & $P$ & X & & & \\
\hline $\begin{array}{l}\text { 20. (Artiles Visbal y García González, } \\
\text { 2000) }\end{array}$ & $\mathrm{X}$ & $X$ & $\mathrm{X}$ & A & $\mathrm{X}$ & $\mathrm{X}$ & & \\
\hline $\begin{array}{l}\text { 21. (JISC, 2002) } \\
\text { Citado por (Uribe Tirado, 2009) }\end{array}$ & X & $X$ & X & $P$ & X & X & & X \\
\hline $\begin{array}{l}\text { 22. (Capmbell, 2002) } \\
\text { Citado por (Rodríguez Castilla, 2007) }\end{array}$ & & $X$ & X & $P$ & X & & & \\
\hline
\end{tabular}




\begin{tabular}{|c|c|c|c|c|c|c|c|c|}
\hline DEFINICIONES & 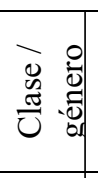 & 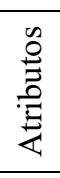 & 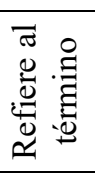 & 孞 & 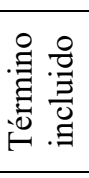 & 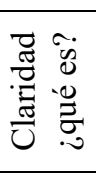 & 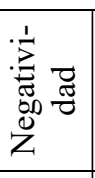 & 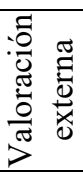 \\
\hline $\begin{array}{l}\text { 23. (Bernhard, 2002) } \\
\text { Citado por (Campal García, 2011) }\end{array}$ & & $\mathrm{X}$ & $\mathrm{X}$ & $\mathrm{A}$ & $X$ & $\mathrm{X}$ & & \\
\hline $\begin{array}{l}\text { 24. (Martí Lahera, 2002) } \\
\text { Citado por (Rodríguez Castilla, 2007) }\end{array}$ & $\mathrm{X}$ & $X$ & $X$ & $\mathrm{~A}$ & $X$ & $\mathrm{X}$ & & \\
\hline 25. (Ponjuán Dante, 2002) & $\mathrm{X}$ & $\mathrm{X}$ & $\mathrm{X}$ & A & $\mathrm{X}$ & $\mathrm{X}$ & & \\
\hline $\begin{array}{l}\text { 26. (Webber y Johnston, 2003) } \\
\text { Citado por (Campal García, 2011) }\end{array}$ & $\mathrm{X}$ & $X$ & $\mathrm{X}$ & $\mathrm{P}$ & & & & \\
\hline $\begin{array}{l}\text { 27. (Breivik, 2003) } \\
\text { Citado por (Uribe Tirado, 2009) }\end{array}$ & $\mathrm{X}$ & $\mathrm{X}$ & $X$ & $\mathrm{P}$ & $\mathrm{X}$ & $\mathrm{X}$ & & \\
\hline $\begin{array}{l}\text { 28. (UNESCO/NFIL, 2003) } \\
\text { Citado por (Uribe Tirado, 2009) }\end{array}$ & & $\mathrm{X}$ & $\mathrm{X}$ & $\mathrm{A}$ & $\mathrm{X}$ & $\mathrm{X}$ & & $\mathrm{X}$ \\
\hline $\begin{array}{l}\text { 29. (NCLI-NFIL, 2003) } \\
\text { Citado por (Uribe Tirado, 2009) }\end{array}$ & & $X$ & $X$ & A & $\mathrm{X}$ & $\mathrm{X}$ & & $\mathrm{X}$ \\
\hline $\begin{array}{l}\text { 30. (Gómez Granados, 2004) } \\
\text { Citado por (Uribe Tirado, 2009) }\end{array}$ & $\mathrm{X}$ & $\mathrm{X}$ & $\mathrm{X}$ & $\mathrm{A}$ & $\mathrm{X}$ & $\mathrm{X}$ & & \\
\hline $\begin{array}{l}\text { 31. (Pinto Molina, 2004) } \\
\text { Citado por (Uribe Tirado, 2009) }\end{array}$ & $\mathrm{X}$ & $\mathrm{X}$ & $\mathrm{X}$ & A & $\mathrm{X}$ & $\mathrm{X}$ & & \\
\hline $\begin{array}{l}\text { 32. (CAUL, 2004) } \\
\text { Citado por (Uribe Tirado, 2009) }\end{array}$ & $\mathrm{X}$ & $\mathrm{X}$ & $X$ & $\mathrm{G}$ & $\mathrm{X}$ & $\mathrm{X}$ & & \\
\hline $\begin{array}{l}\text { 33. (CILIP, 2005) } \\
\text { Citado por (Campal García, 2011) }\end{array}$ & & $\mathrm{X}$ & $\mathrm{X}$ & $\mathrm{A}$ & $\mathrm{X}$ & $\mathrm{X}$ & & $\mathrm{X}$ \\
\hline $\begin{array}{l}\text { 34. (UNESCO/NFIL, 2005) } \\
\text { Citado por (Uribe Tirado, 2009) }\end{array}$ & $\mathrm{X}$ & $\mathrm{X}$ & $\mathrm{X}$ & $\mathrm{G}$ & $\mathrm{X}$ & $\mathrm{X}$ & & $X$ \\
\hline $\begin{array}{l}\text { 35. (Byrne, 2005) } \\
\text { Citado por (Campal García, 2011) }\end{array}$ & $\mathrm{X}$ & $X$ & $X$ & A & $X$ & $\mathrm{X}$ & $\mathrm{X}$ & \\
\hline 36. (Lau y Cats, 2006) & & & $\mathrm{X}$ & $\mathrm{P}$ & & & & \\
\hline 37. (Cabero Almenara et al., 2006) & $\mathrm{X}$ & & $\mathrm{X}$ & A & & & & \\
\hline 38. (Pimienta, 2007) & & $\mathrm{X}$ & $\mathrm{X}$ & A & $\mathrm{X}$ & & & \\
\hline $\begin{array}{l}\text { 39. (Morales Benito, 2007) } \\
\text { Citado por (Campal García, 2011) }\end{array}$ & $\mathrm{X}$ & $X$ & $\mathrm{X}$ & G & $X$ & & $\mathrm{X}$ & \\
\hline $\begin{array}{l}\text { 40. (Ortoll, 2007) } \\
\text { Citado por (Sánchez Tarrago, 2007) }\end{array}$ & $\mathrm{X}$ & $\mathrm{X}$ & $\mathrm{X}$ & A & & $\mathrm{X}$ & & $\mathrm{X}$ \\
\hline 41. (Licea de Arenas, 2007) & & $\mathrm{X}$ & $\mathrm{X}$ & $\mathrm{G}$ & $\mathrm{X}$ & $X$ & & \\
\hline
\end{tabular}




\begin{tabular}{|c|c|c|c|c|c|c|c|c|}
\hline DEFINICIONES & 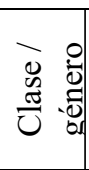 & $\begin{array}{l}\stackrel{\infty}{0} \\
\stackrel{0}{\Xi} \\
\stackrel{0}{E} \\
\text { 是 }\end{array}$ & 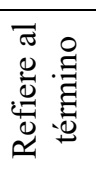 & 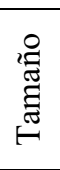 & 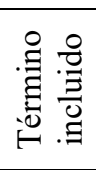 & 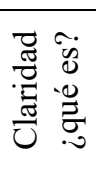 & 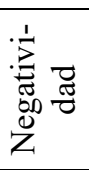 & 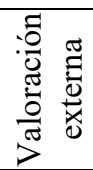 \\
\hline $\begin{array}{l}\text { 42. (REBIUN, 2008) } \\
\text { Citado por (Marzal, 2009) }\end{array}$ & $\mathrm{X}$ & $\mathrm{X}$ & $\mathrm{X}$ & G & $\mathrm{X}$ & $\mathrm{X}$ & & $\mathrm{X}$ \\
\hline $\begin{array}{c}\text { 43. (González } \\
\text { Villavicencio, 2008) }\end{array}$ & $\mathrm{X}$ & $\mathrm{X}$ & $\mathrm{X}$ & A & $\mathrm{X}$ & $\mathrm{X}$ & & \\
\hline 44. (Área Moreira, 2008) & & $\mathrm{X}$ & $\mathrm{X}$ & $\mathrm{P}$ & & & & \\
\hline 45. (Uribe Tirado, 2009) & $\mathrm{X}$ & $\mathrm{X}$ & $\mathrm{X}$ & G & & $\mathrm{X}$ & & $\mathrm{X}$ \\
\hline 46. (Martínez Aldanondo, 2009) & $\mathrm{X}$ & $\mathrm{X}$ & $\mathrm{X}$ & A & $\mathrm{X}$ & $\mathrm{X}$ & & \\
\hline 47. (Campal García, 2010) & $\mathrm{X}$ & & $\mathrm{X}$ & A & $\mathrm{X}$ & & & \\
\hline 48. (Flores Noriega, 2011) & & & $\mathrm{X}$ & $\mathrm{P}$ & $\mathrm{X}$ & & & \\
\hline $\begin{array}{l}\text { 49. (Meneses Placeres y Pinto Molina, } \\
\text { 2011) }\end{array}$ & $\mathrm{X}$ & $\mathrm{X}$ & $\mathrm{X}$ & A & $\mathrm{X}$ & $\mathrm{X}$ & & \\
\hline 50. (Campal García, 2011) & & $\mathrm{X}$ & $\mathrm{X}$ & A & $\mathrm{X}$ & $\mathrm{X}$ & & \\
\hline 51. (Rodríguez Castilla, 2012) & $\mathrm{X}$ & $\mathrm{X}$ & $\mathrm{X}$ & A & & $\mathrm{X}$ & & \\
\hline 52. (Unesco et al., 2012) & $\mathrm{X}$ & $\mathrm{X}$ & $\mathrm{X}$ & G & $\mathrm{X}$ & $\mathrm{X}$ & & $\mathrm{X}$ \\
\hline
\end{tabular}

Tabla I: Comparativa con indicadores seleccionados según las características establecidas.

Después de la evaluación de las definiciones propuestas, se escogieron las que cumplían con la mayor cantidad de indicadores positivos. Dentro de ellas se destacan las de los autores (Bruce, 2003), (Ortoll, 2007), (Uribe tirado, 2009) y (Rodríguez Castila, 2012), subrayando que las definiciones de los autores: Uribe y Ortoll, cuenta con evaluaciones externas.

Es importante aclarar que los criterios fueron aplicados con toda la objetividad del estudio a partir de los indicadores propuestos. Aunque solo 4 de las definiciones cumplían con la mayoría de los indicadores positivos y 2 de ellas corresponden con autores de este artículo, también es importante mencionar otros autores, en su mayoría institucionales, que cuentan con evaluaciones externas, lo cual favorece su aprobación para publicarlas. El indicador que resultó negativo en su evaluación, estuvo centrado en la inclusión del término, o sea, que incluían la palabra de denominación en el contenido.

Dentro de estas definiciones están las de los autores (Council of Library Director, 1997), (AASL, 1998), (UNESCO/NFIL, 2003), (NCLI-NFIL, 2003), (IFLA/UNESCO/ALA, 2012). No obstante, todas las definiciones evaluadas son válidas y reconocidas por la comunidad científica. Se encuentran reflejadas en artículos publicados a través de revistas académicas y fueron evaluadas por expertos en la temática. Constituyen criterios propios de los autores y son respaldados por estudios bibliográficos realizados para cada investigación.

\section{CONCLUSIONES}

El artículo aporta a la comunidad investigativa un análisis exhaustivo de las definiciones relacionadas con la temática ALFIN hasta el año 2012, agrupándolas cronológicamente y ofreciendo datos de valor agregado con respecto a la autoría de cada definición. Todos estos elementos nos permiten concluir que:

- La ALFIN es una temática ampliamente estudiada por diversos investigadores tanto personales como institucionales.

- Cuenta con un amplio respaldo internacional de instituciones reconocidas en el ámbito de la información dentro de las que se destacan la UNESCO, la IFLA y la ALA.

- En todas las definiciones se encontró como término común la palabra "información", lo cual refieren adecuadamente al término que se estudia.

- En 38 definiciones de las 52 analizadas, están presentes los principales elementos de una definición, clasegénero, término, atributos/especificaciones, lo que representa un $73 \%$ de relevancia positiva para el estudio. 
- En 4 de las definiciones analizadas, coincidente con autores personales, se destacan la mayor presencia de los indicadores evaluados.

Para estudios posteriores, se pretende trabajar nuevamente con estas definiciones, pero evaluando los puntos de vista entre los términos de competencias y habilidades. Se pretende incluir, las definiciones publicadas sobre el tema desde el año 2013, a partir de la nueva tendencia de denominación: metaliteracy. Se abordará también la relación entre la cantidad de citas recibidas por estos conceptos en las herramientas de Google Académico y ReserachGate.

\section{BIBLIOGRAFÍA}

---. BP Enseñando y aprendiendo en y con la Web. En: V Congreso Nacional de Bibliotecas Públicas. Gijón. 2010.

---. Propuesta de un programa de Alfabetización Informacional para proyectos productivos en la Universidad de las Ciencias Informáticas. Tutor: Morales., D. R. T. Tesis para optar por el Título de Máster en Gestión de Proyectos Informáticos, Dirección de Información. Universidad de las Ciencias Informáticas, 2007.

AMERICAN ASSOCIATION OF SCHOOL LIBRARIANS. Information Power: Building Partnerships for Learning. Chicago: ALA, Disponible $<$ http://www.ala.org/ala/aasl/aaslproftools/informationpower/informationpower.htm $>$ [Consulta: 11 de enero de 2016].

ÁREA MOREIRA, M. Innovación pedagógica con TIC y el desarrollo de las competencias informacionales y digitales. Investigación en la escuela, 2008, $\mathrm{n}^{\circ}$ 64, p. 518.

ARTILES VISBAL, S. y GARCÍA GONZÁLEZ, F. Cultura informacional. Estrategias para el desarrollo de la sociedad de la información y el conocimiento. Ciencias de la Información, marzo-junio 2000, vol. 31, nº 1-2.

CABERO ALMENARA, J.; LLORENTE CEJUDO, M.C. Capacidades tecnológicas de las TICS por los estudiantes. Enseñanza, 2006, vol. 24, p. $159-175 . \quad$ Disponible en: $<$ http://gredos.usal.es/jspui/bitstream/10366/69608/1/Capacidades_tecnologicas_de_las_TICspor_.pdf $>$ [Consulta: 11 de enero de 2016].

CAMPAL GARCÍA, F. ALFIN en bibliotecas públicas: la dificultad de ver lo obvio. En: Jornada Académica. La alfabetización informacional. Aprendizaje para la vida. Bogotá, Colombia. 29 de septiembre de 2011. p. 7-46.

DOYLE, C.S. Outcome measures for information literacy within the national education goals of 1990: final report of the National Forum on Information Literacy. ACIMED, 1992, vol. 20, $\mathrm{n}^{\mathrm{o}}$ 4, p. 1-22. Disponible en: $<$ http://scielo.sld.cu $>$ [Consulta: 11 de enero de 2016].

FLORES NORIEGA, E. Biblioteca y Docencia: Motivando el Desarrollo de un Programa ALFIN en el Consorcio de Universidades. Alexandría: revista de Ciencias de la Información, enero-diciembre 2011, vol. V, nº 8, p. 53-68.

GONZÁLEZ FERNÁNDEZ-VILLAVICENCIO, N. ALFIN 2.0: Herramientas 2.0 en programas ALFIN en bibliotecas de la Universidad de Sevilla. Boletín de la Asociación Andaluza de Bibliotecarios, julio-diciembre 2008, no 92-93, p. 11-31.

LAU, J. y CATS, R. Hacia unos Indicadores de Alfabetización Informacional. Madrid: Ministerio de Cultura, Disponible en: < http://www.uis.unesco.org/Library/Documents/wp08_InfoLit_en.pdf $>$ [Consulta: 16 de marzo de 2016].

LICEA DE ARENAS, J. La evaluación de la alfabetización informacional. Principios, metodologías y retos. Anales de Documentacion, 2007, $\mathrm{n}^{\mathrm{o}}$ 10, p. 215-232.

MARTÍNEZ ALDANONDO, J. No nos engañes, el conocimiento no se puede gestionar. Aprende RH: la revista de los recursos humanos y del e-learning, 2009, $\mathrm{n}^{\circ} 24$, p. 50-55.

MARZAL, M.A. Evolución conceptual de la alfabetización en información a partir de la alfabetización múltiple en su perspectiva educativa y bibliotecaria. Investigación Bibliotecológica, enero/abril 2009, vol. 23, nº 47.

MENESES PLACERES, G. y PINTO MOLINA, M. Alfinev. Modelo para evaluar la alfabetización informacional en la educación superior en Cuba. Investigación Bibliotecológica, 2011, vol. 25, nº 55, p. 81-106.

PIMIENTA, D. Brecha digital, brecha social, brecha paradigmática. Santo Domingo: Funredes. Disponible en: $<$ http://www.funredes.org/mistica/castellano/ciberoteca/tematica/brecha_paradigmatica.doc $>$ [Consulta: 10 de mayo de 2016].

PONJUÁN DANTE, G. De la Alfabetización a la Cultura Informacional: Rol del profesional de la Información. En: Congreso Internacional de Información “Info 2002”. La Habana. 22 al 26 de abril de 2002.

RODRÍGUEZ CASTILLA, L. Cultura Informacional: el éxito en la Investigación Científica. En: VI Conferencia Cientifica UCIENCIA. II Taller de Sistemas de Gestión de la Información y el Conocimiento. La Habana. Febrero 2012. p. 1-23.

SÁNCHEZ TARRAGO, N. El profesional de la información en los contextos educativos de la sociedad del aprendizaje: espacios y competencias. Acimed, 2007, vol. 12, $\mathrm{n}^{\mathrm{o}}$ 2, Disponible en: $<$ http://bvs.sld.cu/revistas/aci/vol13_2_05/aci02_05.htm> [Consulta: 11 de enero de 2016]. 
UNESCO; IFLA. Declaración de Moscú sobre Alfabetización Mediática e Informacional. Moscú: UNESCO, publicado el: 28 de junio de 2012 última actualización: 28 de junio. 1-4 p.

URIBE TIRADO, A. Interrelaciones entre veinte definiciones-descripciones del concepto de alfabetización en información: propuesta de macro-definición. Acimed, 2009, vol. 20, n⿳⺈ 4, p. 1-22.

WOODY HORTON, F. Information literacy vs. computer literacy, Bulletin of the American Society for Information Science, 1983, vol. 9, $\mathrm{n}^{\text {o }}$ 4, p. 14-16. 


\section{ANEXO}

La siguiente tabla refleja las definiciones seleccionadas para el estudio. La investigación parte de los antecedentes de (URIBE-TIRADO, 2009) y (BAWDEN, 2002). Las tres primeras columnas de la izquierda, muestran las citas de las definiciones analizadas, la definición y los datos sobre el autor (es). Las próximas tres columnas de la derecha, reflejan cuáles fueron utilizadas coincidentemente por los autores que se toman como referentes en el artículo, y las incorporadas en esta investigación.

\begin{tabular}{|c|c|c|c|c|c|}
\hline Autor (es) & Definición & Datos sobre el autor & \begin{tabular}{|c|} 
Bawden, \\
D.
\end{tabular} & $\begin{array}{c}\text { Uribe, } \\
\text { A. }\end{array}$ & $\begin{array}{l}\text { Rodrí- } \\
\text { guez, I. }\end{array}$ \\
\hline (Zurkowski, 1974) & $\begin{array}{l}\text { "Pueden considerarse alfabetizados, competentes en información, las } \\
\text { personas que se han formado en la aplicación de los recursos de } \\
\text { información a su trabajo. Han adquirido las técnicas y las destrezas } \\
\text { necesarias para la utilización de la amplia gama de herramientas } \\
\text { documentales, además de fuentes primarias, en el planteamiento de } \\
\text { soluciones informacionales a sus problemas". Citado por (Campal } \\
\text { García, 2011). }\end{array}$ & $\begin{array}{l}\text { Paul G. Zurkowski - Ex- } \\
\text { Presidente de la Asociación de } \\
\text { Industrias de la Información de } \\
\text { Estados Unidos. Esta definición } \\
\text { también es adoptada por } \\
\text { (Bawden, 2002). }\end{array}$ & $\mathrm{X}$ & & \\
\hline (Owens, 1976) & $\begin{array}{l}\text { "La alfabetización informacional es necesaria para garantizar la } \\
\text { supervivencia de las instituciones democráticas. Todos los hombres } \\
\text { fueron creados igual, pero los votantes con recursos de información están } \\
\text { en situación de tomar decisiones más acertadas que los que son } \\
\text { analfabetos con respecto a la información. La aplicación de los recursos } \\
\text { de información a los procesos de toma de decisiones, para llevar a cabo } \\
\text { responsabilidades cívicas, es una necesidad vital". Citado por (Campal } \\
\text { García, 2011). }\end{array}$ & $\begin{array}{l}\quad \text { Major Robert Owens - } \\
\text { senador y } \\
\text { norteamericano. }\end{array}$ & $\mathrm{X}$ & & \\
\hline (Taylor, 1979) & $\begin{array}{l}\text { "Una definición aproximada incluiría las siguientes premisas: • Que } \\
\text { las soluciones a muchos de los problemas (no a todos) pueden facilitarse } \\
\text { mediante la adquisición de hechos informacionales adecuados. • Que el } \\
\text { conocimiento de la variedad de recursos disponibles (quién y dónde) es } \\
\text { un requisito para esta alfabetización. • Que el proceso de información, } \\
\text { que es continuo, es tan importante como el proceso de información } \\
\text { puntual, que es ocasional. • Que existen unas estrategias de adquisición } \\
\text { de información". Citado por (Campal García, 2011). }\end{array}$ & $\begin{array}{l}\text { Robert S. Taylor - Director } \\
\text { de la Biblioteca del Colegio de } \\
\text { Bibliotecas r Hampshire } \\
\text { Inglaterra, Reino Unido. }\end{array}$ & & & $\mathrm{X}$ \\
\hline (Horton, 1983) & $\begin{array}{l}\text { "La AI se resume en la aplicación de los recursos intelectuales de una } \\
\text { empresa. Los programas de AI convierten a los centros de información } \\
\text { empresarial en centros del saber". (Woody Horton, 1983). }\end{array}$ & $\begin{array}{l}\text { Forest Woody Horton - } \\
\text { Consultor de la Comisión } \\
\text { Nacional de Estados Unidos } \\
\text { sobre Bibliotecas y Ciencias de } \\
\text { la Información (NCLIS). }\end{array}$ & $\mathrm{X}$ & & \\
\hline (Kuhlthau, 1987) & "La ALFIN está totalmente ligada con la alfabetización funcional. & Carol Collier Kuhlthau - & $\mathrm{X}$ & $\mathrm{X}$ & \\
\hline
\end{tabular}




\begin{tabular}{|c|c|c|c|c|c|}
\hline Autor (es) & Definición & Datos sobre el autor & $\begin{array}{c}\text { Bawden, } \\
\text { D. }\end{array}$ & \begin{tabular}{|c|} 
Uribe, \\
A.
\end{tabular} & $\begin{array}{l}\text { Rodrí- } \\
\text { guez, l. }\end{array}$ \\
\hline & $\begin{array}{l}\text { Comprende la habilidad de leer y utilizar información esencial para la } \\
\text { vida diaria. Incluye también el reconocimiento de una necesidad de } \\
\text { información y la búsqueda de información para la toma de decisiones } \\
\text { responsable. La ALFIN requiere la habilidad de gestionar masas } \\
\text { complejas de información generadas por computadoras y medios de } \\
\text { comunicación, así como de saber aprender a lo largo de la vida a medida } \\
\text { que los cambios técnicos y sociales requieran nuevas habilidades y } \\
\text { conocimientos". Citado por (Uribe Tirado, 2009). }\end{array}$ & $\begin{array}{l}\text { Profesora emérita. } \\
\text { Departamento de } \\
\text { Bibliotecología y Ciencias de la } \\
\text { Información, Universidad de } \\
\text { Rutgers. Nueva York, Estados } \\
\text { Unidos. }\end{array}$ & & & \\
\hline (ALA, 1989) & $\begin{array}{l}\text { "Una persona competente en el manejo de la información es la que es } \\
\text { capaz de reconocer cuándo necesita información y tiene la capacidad } \\
\text { para localizar, evaluar y utilizar eficientemente la información requerida, } \\
\text { lo que le permite llegar a ser un aprendiz independiente a lo largo de la } \\
\text { vida". Citado por (Campal García, 2011). }\end{array}$ & $\begin{array}{l}\quad \text { ALA - American Library } \\
\text { Association }- \text { Asociación de } \\
\text { Bibliotecas Americanas. } \\
\text { Illinois, Estados Unidos. }\end{array}$ & $\mathrm{X}$ & $\mathrm{X}$ & \\
\hline (Jackson, 1989) & $\begin{array}{l}\text { "La ALFIN puede definirse como la comprensión del papel y del } \\
\text { poder de la información, tener la habilidad para localizarla, recuperarla y } \\
\text { utilizarla en la toma de decisiones, y tener la habilidad para manipularla } \\
\text { mediante procesos electrónicos". Citado por (Uribe Tirado, 2009). }\end{array}$ & $\begin{array}{l}\text { Nicholas Jackson- } \\
\text { Bibliotecario en Morristown- } \\
\text { Barba School. Miembro del } \\
\text { Comité Presidencial sobre } \\
\text { Informacional. Nueva Jersey, } \\
\text { Estados Unidos. }\end{array}$ & $X$ & $\mathrm{X}$ & \\
\hline (Doyle, C., 1992) & $\begin{array}{l}\text { "Una persona alfabetizada en información es aquella que: } \bullet \text { Reconoce } \\
\text { la necesidad de información. • Sabe que una información precisa y } \\
\text { completa es la base para la toma de decisiones inteligentes. • Identifica } \\
\text { potenciales fuentes de información. } \bullet \text { Desarrolla con éxito las estrategias } \\
\text { de búsqueda. • Accede a fuentes de información, incluidas las basadas en } \\
\text { computadoras y otras tecnologías. } \bullet \text { Evalúa la información. • Organiza la } \\
\text { información para su aplicación práctica. • Integra la nueva información } \\
\text { en su cuerpo de conocimientos. • Utiliza la información para desarrollar } \\
\text { un pensamiento crítico y solucionar problemas". (Doyle, 1992). }\end{array}$ & $\begin{array}{l}\quad \text { Directora Asociada } \\
\text { proyecto de de Tecnologías } \\
\text { California y Directora del } \\
\text { proyecto Telemation. }\end{array}$ & & $\mathrm{X}$ & \\
\hline $\begin{array}{l}\text { (Lenox, M.f. y Walker, } \\
\text { M.1., 1993) }\end{array}$ & $\begin{array}{l}\text { "La persona alfabetizada en información es aquella que: tiene } \\
\text { habilidades y capacidad de análisis crítico para formular preguntas de } \\
\text { investigación y evaluar los resultados, y las habilidades para buscar y } \\
\text { acceder a una variedad de tipos de información con el objetivo de } \\
\text { satisfacer sus necesidades de información". Citado por (Uribe Tirado, } \\
\text { 2009). }\end{array}$ & $\begin{array}{l}\text { Mary F. Lenox y Michael L. } \\
\text { Walker - Profesores de la } \\
\text { Facultad de Biblioteconomía y } \\
\text { Documentación de la } \\
\text { Universidad de Missouri- } \\
\text { Columbia. }\end{array}$ & $\mathrm{X}$ & $\mathrm{X}$ & \\
\hline (Behrens, 1994) & $\begin{array}{l}\text { "Una persona culta informacionalmente es capaz de: • Determinar } \\
\text { cuándo hay una necesidad de información. • Identificar cuál es la } \\
\text { información que se necesita. • Encontrar la información precisada. • } \\
\text { Evaluarla en términos de referencia. • Organizarla para que resulte útil en }\end{array}$ & $\begin{array}{l}\text { Shirley Behrens - Profesora } \\
\text { titular en el Departamento de } \\
\text { Ciencias de la Información en la } \\
\text { Universidad de Sudáfrica. }\end{array}$ & $X$ & & \\
\hline
\end{tabular}




\begin{tabular}{|c|c|c|c|c|c|}
\hline Autor (es) & Definición & Datos sobre el autor & \begin{tabular}{|} 
Bawden, \\
D.
\end{tabular} & \begin{tabular}{c|} 
Uribe, \\
A.
\end{tabular} & $\begin{array}{l}\text { Rodrí- } \\
\text { guez, l. }\end{array}$ \\
\hline & $\begin{array}{l}\text { la solución del problema. • Aplicarla de manera eficiente". Citado por } \\
\text { (Campal García, 2011). }\end{array}$ & & & & \\
\hline (Ford, 1994) & $\begin{array}{l}\text { "Alfabetización informativa es saber cuándo se necesita información } \\
\text { y tener la capacidad de localizar, evaluar y usar la información necesaria } \\
\text { de un modo eficaz y comunicarla. Es un concepto provocativo a la hora } \\
\text { de dirigirse a un público variado y cambiante, con distinta preparación } \\
\text { para el uso de las bibliotecas". Citado por (Campal García, 2011). }\end{array}$ & 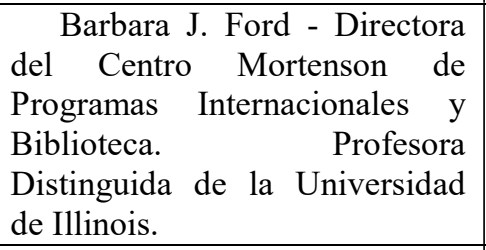 & $\mathrm{X}$ & & \\
\hline \begin{tabular}{l}
\multicolumn{1}{c}{ (Commission $r$} \\
Colleges, Southern \\
Association of Colleges and \\
Schools (SACS), 1996)
\end{tabular} & $\begin{array}{l}\text { "Habilidad para localizar, evaluar y usar información para aprender } \\
\text { de por vida en forma independiente". Citado por (Ponjuán Dante, 2002). }\end{array}$ & $\begin{array}{l}\text { Comisión de Universidades } \\
\text { de la Asociación Sureña de } \\
\text { Colegios y Escuelas. }\end{array}$ & & & X \\
\hline (Shapiro y Hughes, 1996) & $\begin{array}{l}\text { "La ALFIN implica la reflexión crítica sobre la naturaleza de la } \\
\text { información, su infraestructura técnica y su contexto e impacto cultural, } \\
\text { social e incluso filosófico. Para estos autores, la ALFIN debe concebirse } \\
\text { más ampliamente y como un nuevo arte liberal que comprende desde } \\
\text { conocer cómo se utilizan las computadoras y se accede a la información } \\
\text { hasta la realización de una reflexión crítica sobre la naturaleza de la } \\
\text { información, su infraestructura técnica, social y cultural e incluso } \\
\text { filosófica y su impacto en un contexto". Citado por (Uribe Tirado, 2009). }\end{array}$ & 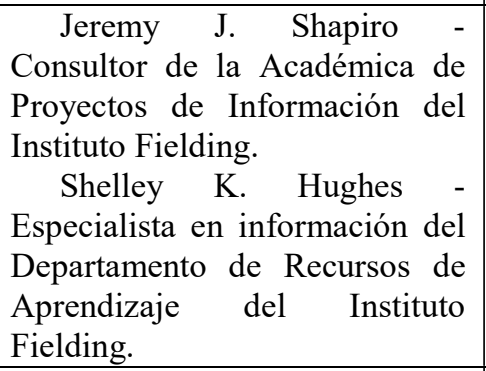 & $\mathrm{X}$ & $\mathrm{X}$ & \\
\hline $\begin{array}{l}\text { (Council of Library } \\
\text { Directors, 1997) }\end{array}$ & $\begin{array}{l}\text { "Alfabetización Informacional. Habilidades para reconocer cuando se } \\
\text { necesita información y para localizar, evaluar, usar eficientemente y } \\
\text { comunicar información en sus diferentes formatos". Citado por (Ponjuán } \\
\text { Dante, 2002). }\end{array}$ & $\begin{array}{l}\text { Consejo de Administración } \\
\text { de Bibliotecas. California State } \\
\text { University. }\end{array}$ & & & $\mathrm{X}$ \\
\hline (Bruce, 1997) & $\begin{array}{l}\text { "Está esencialmente asociada a la práctica con la información y con } \\
\text { el pensamiento crítico en el ambiente de las tecnologías de la } \\
\text { información. Es el conjunto de aptitudes para localizar, manejar y utilizar } \\
\text { la información de forma eficaz para una gran variedad de necesidades". } \\
\text { Citado por (Uribe Tirado, 2009). }\end{array}$ & $\begin{array}{l}\text { Christine Bruce - Profesora } \\
\text { asociada de la Universidad } \\
\text { Tecnológica de Queensland. } \\
\text { Facultad de Tecnología de la } \\
\text { Información. Enseñanza de la } \\
\text { alfabetización informacional. }\end{array}$ & $\mathrm{X}$ & $\mathrm{X}$ & \\
\hline (OCDE, 1998) & $\begin{array}{l}\text { "La habilidad para entender y emplear información en las actividades } \\
\text { diarias, en el hogar, en el trabajo y en los actos sociales, con la finalidad } \\
\text { de cumplir los objetivos de uno, y de desarrollar el conocimiento y el } \\
\text { potencial de uno mismo". Citado por (Campal García, 2011). }\end{array}$ & $\begin{array}{l}\text { Organización para la } \\
\text { Cooperación y el Desarrollo } \\
\text { Económico, con sede en París, } \\
\text { Francia. Agrupa a } 34 \text { países. }\end{array}$ & & $\mathrm{X}$ & \\
\hline (AASL, 1998) & $\begin{array}{l}\text { "La competencia informacional ha sido definida como la habilidad de } \\
\text { reconocer una necesidad de información y la capacidad de identificar, } \\
\text { localizar, evaluar, organizar, comunicar y utilizar la información de }\end{array}$ & $\begin{array}{l}\text { American Association of } \\
\text { School Libraries- Asociación } \\
\text { Americana de Bibliotecarios }\end{array}$ & & & $\mathrm{X}$ \\
\hline
\end{tabular}




\begin{tabular}{|c|c|c|c|c|c|}
\hline Autor (es) & Definición & Datos sobre el autor & \begin{tabular}{|c|} 
Bawden, \\
D.
\end{tabular} & $\begin{array}{c}\text { Uribe, } \\
\text { A. }\end{array}$ & $\begin{array}{l}\text { Rodrí- } \\
\text { guez, } 1 .\end{array}$ \\
\hline & $\begin{array}{l}\text { forma efectiva, tanto para la resolución de problemas como para el } \\
\text { aprendizaje a lo largo de la vida". (American Association of School } \\
\text { Librarians, 1998). }\end{array}$ & Escolares & & & \\
\hline $\begin{array}{l}\quad \text { (Canada, Ministry of } \\
\text { Education and Training, } \\
\text { 1999) }\end{array}$ & $\begin{array}{l}\text { "Alfabetismo en información es la capacidad de adquirir, evaluar en } \\
\text { forma crítica, seleccionar, usar, crear y comunicar información de modo } \\
\text { tal que conduzca al conocimiento y a la sabiduría". Citado por (Campal } \\
\text { García, 2011). }\end{array}$ & $\begin{array}{l}\text { Ministerio de Educación y } \\
\text { Formación de Canadá. }\end{array}$ & & & $\mathrm{X}$ \\
\hline (Bundy A, 2000) & $\begin{array}{l}\text { "La ALFIN es la capacidad para reconocer la necesidad de } \\
\text { información y después identificar cuál es la que se necesita, acceder a } \\
\text { ella, evaluarla y aplicarla cuándo y dónde se requiere". Citado por (Uribe } \\
\text { Tirado, 2009). }\end{array}$ & $\begin{array}{l}\text { Alan Bundy- Profesor de la } \\
\text { Universidad del Sur de } \\
\text { Australia. Centro de Estudios de } \\
\text { la Información. }\end{array}$ & & $\mathrm{X}$ & \\
\hline $\begin{array}{l}\text { (Artiles Visbal y García } \\
\text { González, 2000) }\end{array}$ & $\begin{array}{l}\text { "Por cultura informacional se entiende la habilidad de entender y } \\
\text { emplear información impresa en las actividades diarias, en el hogar, en el } \\
\text { trabajo, y en los actos sociales, con la finalidad de cumplir los objetivos } \\
\text { de uno, y de desarrollar el conocimiento y el potencial de uno mismo". } \\
\text { (Artiles Visbal y García González, 2000). }\end{array}$ & $\begin{array}{l}\text { Sara Artiles Visbal y Fidel } \\
\text { García González. Consultores } \\
\text { de GECYT. (Empresa de } \\
\text { Gestión, el Conocimiento y la } \\
\text { Innovación). Cuba. }\end{array}$ & & & $\mathrm{X}$ \\
\hline $\begin{array}{l}\quad \text { The Joint Information } \\
\text { Services } \\
\text { 2002) }\end{array}$ & $\begin{array}{l}\text { "La ALFIN es la capacidad de identificar, evaluar, recuperar, evaluar, } \\
\text { adaptar, organizar y comunicar información en un contexto iterativo de } \\
\text { revisión y reflexión". Citado por (Uribe Tirado, 2009) }\end{array}$ & $\begin{array}{l}\text { Comité Mixto de Servicios } \\
\text { de Información. Reino Unido. }\end{array}$ & & $X$ & \\
\hline (Capmbell, 2002) & $\begin{array}{l}\text { "Para una sociedad tecnológicamente avanzada, el objetivo es una } \\
\text { alfabetización activa, que permita a la gente utilizar el lenguaje para } \\
\text { aumentar su capacidad de pensar, crear e interrogar, de manera que } \\
\text { verdaderamente participen en la sociedad". Citado por (Rodríguez } \\
\text { Castilla, 2007). }\end{array}$ & $\begin{array}{l}\text { Patricia J. Campbell - } \\
\text { Universidad de West Georgia. } \\
\text { Carrollton, EE.UU. }\end{array}$ & & & $\mathrm{X}$ \\
\hline (Bernhard, 2002) & $\begin{array}{l}\text { "La alfabetización informativa es necesaria para compensar las } \\
\text { desigualdades en el acceso a la información evitando, en lo posible, la } \\
\text { creación de una élite: • Identificación de la necesidad de información. } \\
\text { Creación y organización de la información. • Estrategias de búsqueda de } \\
\text { información. - Habilidades tecnológicas e informáticas. • Evaluación y } \\
\text { tratamiento de la información. - Utilización y comunicación de la } \\
\text { información. • Aspectos éticos y sociales. • Actitud activa para el } \\
\text { aprendizaje durante toda la vida. • Crítica de los medios de } \\
\text { comunicación. • Autoevaluación". Citado por (Campal García, 2011). }\end{array}$ & $\begin{array}{l}\text { Paulette Bernhard - Escuela } \\
\text { de Biblioteconomía y Ciencias } \\
\text { de la Información en Montreal. } \\
\text { Québec, Canadá. }\end{array}$ & & & $X$ \\
\hline (Martí Lahera, 2002) & $\begin{array}{l}\text { "Cultura informacional como un conjunto de conocimientos, valores } \\
\text { y hábitos que, complementados con el uso de prácticas y herramientas de } \\
\text { gestión de información en el actuar diario, permite a los miembros de } \\
\text { una organización o sociedad aportar los retos que se presentan en el } \\
\text { cumplimiento de los objetivos y metas a nivel micro y macro social". }\end{array}$ & \begin{tabular}{lcc}
\multicolumn{2}{c}{ Yohany } & Marti Lahera \\
Máster en Ciencias de la \\
Información. Facultad & de \\
Comunicación de & la \\
Universidad de la Habana. & \\
\end{tabular} & & & $\mathrm{X}$ \\
\hline
\end{tabular}

Anales de Documentación, 2016, vol. 19, $\mathrm{n}^{\circ} 2$ 


\begin{tabular}{|c|c|c|c|c|c|}
\hline Autor (es) & Definición & Datos sobre el autor & \begin{tabular}{|} 
Bawden, \\
D.
\end{tabular} & $\begin{array}{c}\text { Uribe, } \\
\text { A. }\end{array}$ & $\begin{array}{l}\text { Rodrí- } \\
\text { guez, l. }\end{array}$ \\
\hline & Citado por (Rodríguez Castilla, 2007). & & & & \\
\hline (Ponjuán Dante, 2002) & $\begin{array}{l}\text { "Cultura informacional, por tanto, constituye una categoría } \\
\text { jerárquicamente superior a la de alfabetismo informacional. El proceso } \\
\text { continuo de alfabetización, crea ese patrón que provoca una constante } \\
\text { aproximación al cambio, esa cultura. Crear, provocar esas relaciones } \\
\text { sociales, es indispensable para masificar las condiciones que vayan } \\
\text { sembrando las condiciones donde determinados actores pueden ejercer la } \\
\text { función de agentes de cambio". (Ponjuán Dante, 2002). }\end{array}$ & $\begin{array}{l}\text { Gloria Ponjuán Dante - Dr. } \\
\text { Ciencias de la Información, } \\
\text { Facultad de Comunicación } \\
\text { Universidad de La Habana. }\end{array}$ & & & $\mathrm{X}$ \\
\hline $\begin{array}{l}\text { (Webber y Johnston, } \\
\text { 2003) }\end{array}$ & $\begin{array}{l}\text { "Adopción de conducta adecuada en relación con la información, } \\
\text { para identificar por cualquier medio o canal información ajustada a la } \\
\text { necesidad, y que conduce a un uso sabio y ético de la información en la } \\
\text { sociedad". Citado por (Campal García, 2011). }\end{array}$ & 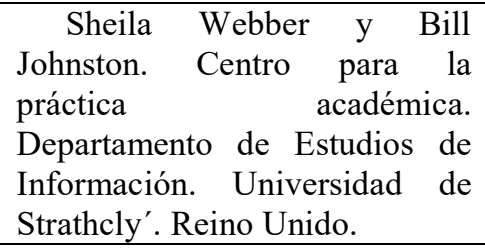 & $\mathrm{X}$ & $X$ & \\
\hline (Breivik, 2003) & $\begin{array}{l}\text { "La ALFIN es un conjunto integrado de habilidades (estrategias de } \\
\text { investigación y evaluación), conocimientos de herramientas y recursos, } \\
\text { desenvueltos a partir de determinadas actitudes". Citado por (Uribe } \\
\text { Tirado, 2009). }\end{array}$ & $\begin{array}{l}\text { Patrica S. Breivik,- Decana } \\
\text { de la Biblioteca de la } \\
\text { Universidad Estatal de San José. } \\
\text { Estados Unidos. }\end{array}$ & & $\mathrm{X}$ & \\
\hline (UNESCO/NFIL, 2003) & $\begin{array}{l}\text { "La ALFIN abarca la conciencia de los propios problemas y } \\
\text { necesidades de información, y la capacidad de identificar, localizar, } \\
\text { evaluar, organizar y crear, utilizar y comunicar con eficacia la } \\
\text { información para afrontar las cuestiones o problemas que se presenten; } \\
\text { constituye un prerrequisito para la participación efectiva en la sociedad } \\
\text { de la información, y forma parte del derecho humano básico al } \\
\text { aprendizaje a lo largo de la vida". Citado por (Uribe Tirado, 2009). } \\
\text { Declaración de Praga. Esta definición es asumida también por la } \\
\text { autora (Cisneros, 2007). Especialista en Ciencias de la Información. } \\
\text { Infomed, Cuba. }\end{array}$ & $\begin{array}{l}\text { Organización de las } \\
\text { Naciones Unidas para la } \\
\text { Educación, la Ciencia y la } \\
\text { Cultura. } \\
\quad \text { Foro Nacional de } \\
\text { Alfabetización Informacional. } \\
\text { Estados Unidos. }\end{array}$ & & $\mathrm{X}$ & \\
\hline $\begin{array}{l}\text { (Us National Commission } \\
\text { on Libraries and Information } \\
\text { Science y The National } \\
\text { Forum on Information } \\
\text { Literacy, 2003) }\end{array}$ & $\begin{array}{l}\text { "La ALFIN comprende el conocimiento de los intereses y } \\
\text { necesidades de información de todos, y la capacidad de identificar, } \\
\text { localizar, evaluar, organizar y crear con efectividad, así como utilizar y } \\
\text { transmitir la información para tratar los asuntos o problemas en cuestión; } \\
\text { es un requisito previo para participar de forma eficaz en la sociedad de la } \\
\text { información, y forma parte del derecho humano fundamental de aprender } \\
\text { de modo continuo". Citado por (Uribe Tirado, 2009). }\end{array}$ & \begin{tabular}{l}
\multicolumn{1}{c}{ Comisión Nacional de } \\
Bibliotecas y Ciencias de la \\
Información. Foro Nacional de \\
Alfabetización Informacional. \\
Estados Unidos.
\end{tabular} & & $\mathrm{X}$ & \\
\hline (Gómez Granados, 2004) & $\begin{array}{l}\text { "Utilizamos la expresión ALFIN para referirnos a las competencias, } \\
\text { aptitudes, conocimientos y valores necesarios para acceder, utilizar y } \\
\text { comunicar la información en cualquiera de sus formas, con fines de }\end{array}$ & \begin{tabular}{llr}
\multicolumn{1}{c}{ Manuel Gómez Granados - } \\
Director General. Instituto \\
Mexicano de Doctrina Social
\end{tabular} & & $\mathrm{X}$ & \\
\hline
\end{tabular}




\begin{tabular}{|c|c|c|c|c|c|}
\hline Autor (es) & Definición & Datos sobre el autor & $\begin{array}{l}\text { Bawden, } \\
\text { D. }\end{array}$ & $\begin{array}{c}\text { Uribe, } \\
\text { A. }\end{array}$ & $\begin{array}{l}\text { Rodrí- } \\
\text { guez, l. }\end{array}$ \\
\hline & $\begin{array}{l}\text { estudio, investigación, o ejercicio profesional. Entendemos la ALFIN } \\
\text { como el conocimiento y la capacidad de emplear de modo reflexivo e } \\
\text { intencional el conjunto de conceptos, procedimientos y actitudes } \\
\text { involucrados en el proceso de obtener, evaluar, utilizar y comunicar la } \\
\text { información por medios convencionales y electrónicos". Citado por } \\
\text { (Uribe Tirado, 2009). }\end{array}$ & Cristiana. & & & \\
\hline (Pinto Molina, 2004) & $\begin{array}{l}\text { "Alfabetización informacional es el aprendizaje de habilidades, } \\
\text { competencias, conocimientos y valores para el acceso, uso y } \\
\text { comunicación de la información en cualquiera de sus formas, con el fin } \\
\text { de generar estudiantes competentes, entrenados en el hábito de saber } \\
\text { explorar los caminos de la información, de reconocer sus cualidades, } \\
\text { bondades y debilidades, saber buscar con atino, saber evaluar y } \\
\text { seleccionar la información pertinente, saber integrar la información } \\
\text { nueva para generar conocimiento y saber usarla debidamente". Citado } \\
\text { por (Uribe Tirado, 2009). }\end{array}$ & $\begin{array}{l}\text { María Pinto Molina - } \\
\text { Catedrática de Documentación. } \\
\text { Facultad de Biblioteconomía y } \\
\text { Documentación. Universidad de } \\
\text { Granada. España. }\end{array}$ & & $\mathrm{X}$ & \\
\hline $\begin{array}{l}\text { (Council of Australian } \\
\text { University Librarians, 2004) }\end{array}$ & $\begin{array}{l}\text { "La alfabetización en información es un pre-requisito para el } \\
\text { aprendizaje continuo a lo largo de toda la vida y es común a todas las } \\
\text { disciplinas, a todos los entornos de aprendizaje y a todos los niveles } \\
\text { educativos. Capacita a quien aprende para enfrentarse críticamente con } \\
\text { los contenidos y ampliar sus investigaciones, para hacerse más } \\
\text { autosuficiente y asumir un mayor control sobre su propio proceso de } \\
\text { aprendizaje. Es una capacidad de comprender y un conjunto de } \\
\text { habilidades que capacitan a los individuos para reconocer cuándo se } \\
\text { necesita información y poseer la capacidad de localizar, evaluar y utilizar } \\
\text { eficazmente la información requerida". Citado por (Uribe Tirado, 2009). } \\
\text { Se apoyan en la definición de la (American Library Association, } \\
\text { 1989). }\end{array}$ & $\begin{array}{l}\text { Consejo de Bibliotecarios de } \\
\text { la Universidad de Australia. } \\
\text { Asociación de Bibliotecarios } \\
\text { Americanos. }\end{array}$ & & $\mathrm{X}$ & \\
\hline $\begin{array}{l}\text { (Chartered Institute of } \\
\text { Library and Information } \\
\text { Professionals CILIP, 2005) }\end{array}$ & $\begin{array}{l}\text { "ALFIN es saber cuándo y por qué necesitamos información, dónde } \\
\text { encontrarla y cómo evaluarla, usarla y comunicarla de manera ética. } \\
\text { Implica la comprensión de: La necesidad de información. Los recursos } \\
\text { disponibles. Cómo encontrar la información. La necesidad de evaluar los } \\
\text { resultados. Cómo trabajar con los resultados y explotarlos. La ética y } \\
\text { responsabilidad en la utilización. Cómo comunicar y compartir los } \\
\text { resultados. Cómo gestionar lo encontrado". Citado por (Campal García, } \\
2011 \text { ). }\end{array}$ & $\begin{array}{l}\text { Instituto de Profesionales de } \\
\text { Bibliotecología y Ciencias de la } \\
\text { Información. Reino Unido. }\end{array}$ & & & $\mathrm{X}$ \\
\hline (UNESCO/NFIL, 2005) & $\begin{array}{l}\text { "La ALFIN se encuentra en el corazón del aprendizaje a lo largo de } \\
\text { la vida. Capacita a la gente de toda clase y condición para buscar, } \\
\text { evaluar, utilizar y crear información eficazmente para conseguir sus }\end{array}$ & 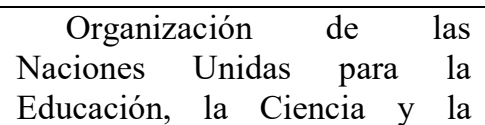 & & $\mathrm{X}$ & \\
\hline
\end{tabular}




\begin{tabular}{|c|c|c|c|c|c|}
\hline Autor (es) & Definición & Datos sobre el autor & \begin{tabular}{|} 
Bawden, \\
D.
\end{tabular} & $\begin{array}{c}\text { Uribe, } \\
\text { A. }\end{array}$ & $\begin{array}{l}\text { Rodrí- } \\
\text { guez, } 1 .\end{array}$ \\
\hline & $\begin{array}{l}\text { metas personales, sociales, ocupacionales y educativas. Constituye un } \\
\text { derecho humano básico en el mundo digital y promueve la inclusión } \\
\text { social de todas las naciones. El aprendizaje a lo largo de la vida permite } \\
\text { que los individuos, las comunidades y las naciones alcancen sus } \\
\text { objetivos y aprovechen las oportunidades que surgen en un entorno } \\
\text { global en desarrollo para beneficios compartidos. Ayuda a las personas y } \\
\text { a sus instituciones a afrontar los retos tecnológicos, económicos y } \\
\text { sociales, a remediar las desventajas y a mejorar el bienestar de todos". } \\
\text { Citado por (Uribe Tirado, 2009). } \\
\text { Declaración de Alejandría sobre alfabetización. }\end{array}$ & $\begin{array}{l}\text { Cultura. } \\
\quad \text { Foro Nacional de } \\
\text { Alfabetización Informacional. } \\
\text { Estados Unidos. }\end{array}$ & & & \\
\hline (Byrne, 2005) & $\begin{array}{l}\text { "La ALFIN es la capacidad de acceder, valorar y utilizar la } \\
\text { información de manera eficaz en la vida diaria. No es una propiedad de } \\
\text { las tecnologías de la información, ni de las publicaciones, ni de la cultura } \\
\text { literaria. Es un conjunto de capacidades, habilidades, conductas y } \\
\text { actitudes que trasciende al medio utilizado para el intercambio de la } \\
\text { información al tiempo que le facilita su propia eficacia. Por consiguiente, } \\
\text { resulta tan importante en una cultura oral como en una documental". } \\
\text { Citado por (Campal García, 2011). }\end{array}$ & $\begin{array}{l}\text { Alex Byrne - Ex-Presidente } \\
\text { electo de la IFLA. }\end{array}$ & & & $\mathrm{X}$ \\
\hline (Lau, 2006) & $\begin{array}{l}\text { "Dominio de la información, educación de usuarios. Instrucción } \\
\text { biográfica. Orientación bibliotecaria. Competencias informacionales. } \\
\text { Capacitación de usuarios. Desarrollo de habilidades informacionales". } \\
\text { Citado por (Lau y Cats, 2006). }\end{array}$ & $\begin{array}{l}\text { Lau, Jesús - Ex-Presidente } \\
\text { de la Sección de ALFIN en la } \\
\text { IFLA - Federación Internacional } \\
\text { de Asociaciones de } \\
\text { Bibliotecarios e Instituciones. }\end{array}$ & & & $\mathrm{X}$ \\
\hline $\begin{array}{c}\text { (Cabrero Almenara y } \\
\text { Llorente Cejudo, 2006) }\end{array}$ & $\begin{array}{l}\text { "Se refiera a un sofisticado repertorio de competencias que } \\
\text { impregnan el lugar de trabajo, la comunidad y la vida social, entre las } \\
\text { que se incluyen las habilidades necesarias para manejar la información y } \\
\text { la capacidad de evaluar la relevancia y la fiabilidad de lo que busca en } \\
\text { internet". Citado por (Cabero Almenara et al., 2006). }\end{array}$ & $\begin{array}{l}\text { Julio Cabero Almenara, } \\
\text { María del Carmen Llorente } \\
\text { Cejudo, Verónica Marín Díaz. } \\
\text { Profesores de la Universidad de } \\
\text { Sevilla. España. Coincide con } \\
\text { los criterios de (OCDE }(2003)) \text {. }\end{array}$ & & & $\mathrm{X}$ \\
\hline (Pimienta, 2007) & $\begin{array}{l}\text { "La alfabetización digital consiste en: } \bullet \text { El manejo de las } \\
\text { infraestructuras técnicas. } \bullet \text { Las habilidades para usar las aplicaciones } \\
\text { informáticas. • Los conceptos fundamentales sobre redes e información. } \\
\text { Las habilidades intelectuales para solicitar la tecnología de la } \\
\text { información cuando se necesita". (Pimienta, 2007). }\end{array}$ & $\begin{array}{l}\quad \text { Daniel Pimienta. } \\
\text { Matemático. Dr. en Ciencias } \\
\text { Informáticas. Creador de la } \\
\text { Fundación Redes y Desarrollo. }\end{array}$ & & & $\mathrm{X}$ \\
\hline (Benito Morales, 2007) & $\begin{array}{l}\text { "Alfabetizar en información es mucho más que: • Desarrollar cursos } \\
\text { de informática y acceso a internet. • Desarrollar programas de formación } \\
\text { de usuarios de bibliotecas. • Desarrollar actividades de animación } \\
\text { lectora. • Desarrollar experiencias didácticas basadas en el aprendizaje }\end{array}$ & $\begin{array}{l}\text { Félix Morales Benito. Dr. en } \\
\text { Biblioteconomía. España. }\end{array}$ & & & $\mathrm{X}$ \\
\hline
\end{tabular}

"La ALFIN es la capacidad de acceder, valorar y utilizar la iteraria. Es un conjunto de capacidades, habilidades, conductas y do por (Campal García, 2011) Capacitación de usuarios. Desarrollo de habilidades informacionales". internet”. Citado por (Cabero Almenara et al., 2006). informáticas. • Los conceptos fundamentales sobre redes e información. • Las habilidades intelectuales para solicitar la tecnología de la

"Alfabetizar en información es mucho más que: • Desarrollar cursos de usuarios de bibliotecas. - Desarrollar actividades de animación lectora. - Desarrollar experiencias didácticas basadas en el aprendizaje 


\begin{tabular}{|c|c|c|c|c|c|}
\hline Autor (es) & Definición & Datos sobre el autor & \begin{tabular}{|c|} 
Bawden, \\
D.
\end{tabular} & $\begin{array}{c}\text { Uribe, } \\
\text { A. }\end{array}$ & $\begin{array}{l}\text { Rodrí- } \\
\text { guez, l. }\end{array}$ \\
\hline & $\begin{array}{l}\text { por proyectos, buscando información en distintas fuentes. - Desarrollar } \\
\text { una mediateca escolar con numerosos fondos y un eficaz servicio de } \\
\text { préstamo. Implica aplicar un modelo psicopedagógico para el } \\
\text { aprendizaje a lo largo de la vida, concibiendo la instrucción escolar } \\
\text { desde una triple perspectiva: Aprender a pensar. Aprender a informarse. } \\
\text { Aprender a vivir, tal como lo establece en su modelo de educación } \\
\text { documental". Citado por (Campal García, 2011). }\end{array}$ & & & & \\
\hline (Ortoll, 2007) & $\begin{array}{l}\text { "Para denominar al conjunto de habilidades, destrezas, capacidades, } \\
\text { para utilizar de manera creativa y eficaz la información en idioma } \\
\text { español, se utilizan términos como cultura informacional, habilidades } \\
\text { informativas, alfabetización informacional o competencia informacional. } \\
\text { A pesar de las posibles diferencias entre las citadas expresiones, puede } \\
\text { apreciarse un elemento común que subyace en todas ellas: la idea de } \\
\text { relacionarse de manera efectiva con el mundo de la información". Citado } \\
\text { por (Sánchez Tarrago, 2007). } \\
\text { La autora (Sánchez Tarragó, 2007) Lic. ICTB. Asistente adjunta } \\
\text { Facultad de Comunicación. Infomed. Se apoya es la definición de Ortoll. }\end{array}$ & $\begin{array}{l}\quad \text { Doctora en Sistemas de } \\
\text { Información y Documentación - } \\
\text { Universidad de Zaragoza. } \\
\text { Profesora de los Estudios de } \\
\text { Ciencias de la Información y de } \\
\text { la Comunicación -UOC. }\end{array}$ & & & $\mathrm{X}$ \\
\hline (Licea de Arenas, 2007) & $\begin{array}{l}\text { "Las competencias en información tienen una repercusión directa } \\
\text { sobre los conocimientos, las habilidades y las aptitudes: } \\
\text { Realizar búsquedas en línea. - Seleccionar los recursos de } \\
\text { información. - Citar correctamente. - Identificar el uso correcto que debe } \\
\text { dársele a la información. } \\
\text { Habilidades: - Utilizar los operadores booleanos. - Localizar los } \\
\text { materiales en la biblioteca, ordenados de acuerdo con algún sistema de } \\
\text { clasificación. - Hacer mapas mentales. - Registrar bibliográficamente los } \\
\text { recursos a utilizar. - Distinguir las fuentes de información: primarias, } \\
\text { secundarias y terciarias. Actitudes: - Entusiasmo por el uso de los libros } \\
\text { y la biblioteca. - Sentido de pertenencia a la comunidad de usuarios de la } \\
\text { biblioteca. - Actitud positiva hacia los libros y las bibliotecas como } \\
\text { fuente de aprendizaje y no como un almacén. - Satisfacción al leer. - } \\
\text { Compartir experiencias de lectura. - Considerar a los autores de libros } \\
\text { como seres reales. - Ver el ordenamiento de la biblioteca como algo } \\
\text { indispensable". (Licea de Arenas, 2007). }\end{array}$ & 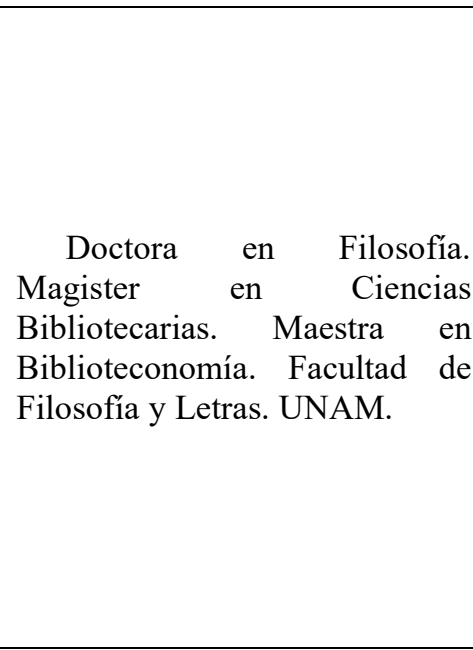 & & & $\mathrm{X}$ \\
\hline (REBIUN, 2008) & $\begin{array}{l}\text { "La formación en competencias informacionales se podría definir } \\
\text { como un conjunto de competencias más complejas que el mero uso de } \\
\text { TIC para realizar búsquedas y consultas de información. En estas } \\
\text { competencias están implicados tanto habilidades de búsqueda, selección, } \\
\text { análisis crítico, reelaboración y comunicación de información, como el }\end{array}$ & $\begin{array}{l}\text { Red de } \quad \text { Bibliotecas } \\
\text { Universitarias de España. }\end{array}$ & & & $\mathrm{X}$ \\
\hline
\end{tabular}




\begin{tabular}{|c|c|c|c|c|c|}
\hline Autor (es) & Definición & Datos sobre el autor & \begin{tabular}{|c|} 
Bawden, \\
D.
\end{tabular} & \begin{tabular}{|c|} 
Uribe, \\
A.
\end{tabular} & $\begin{array}{l}\text { Rodrí- } \\
\text { guez, l. }\end{array}$ \\
\hline & $\begin{array}{l}\text { desarrollo de actitudes éticas hacia el uso de la misma. Asimismo, esta } \\
\text { alfabetización tiene en cuenta tanto los distintos soportes materiales de la } \\
\text { información (sean impresos, audiovisuales o digitales), como las formas } \\
\text { de representación o lenguajes de codificación de la información } \\
\text { textuales, icónicos, hipertextuales, multimedia). Se destaca que lo } \\
\text { relevante no sólo es adquirir las habilidades instrumentales en la } \\
\text { búsqueda y acceso a la información, sino también y sobre todo, saber } \\
\text { realizar un uso inteligente de la información en distintos contextos de } \\
\text { uso". Citado por (Marzal, 2009). }\end{array}$ & & & & \\
\hline (Nieves González, 2008) & $\begin{array}{l}\text { "Unifica las competencias informacionales y las tecnológicas o } \\
\text { digitales, el pensamiento crítico y las habilidades de interacción online, } \\
\text { para construir un único perfil de competencias digitales, en información } \\
\text { digital y que podemos concretar en saber encontrar, evaluar y usar la } \\
\text { información digital de forma eficaz, eficiente y ética". (González } \\
\text { Fernández-Villavicencio, 2008). }\end{array}$ & $\begin{array}{l}\quad \text { Profesora } \\
\text { Biblioteconomía en re la } \\
\text { Universidad Pablo de Olavide, } \\
\text { (Sevilla) y bibliotecaria en la } \\
\text { USE. }\end{array}$ & & & $\mathrm{X}$ \\
\hline (Área Moreira, 2008) & $\begin{array}{l}\text { "Un ciudadano del siglo XXI debe estar formado en las competencias } \\
\text { para el acceso y uso inteligente y ético de la información y la } \\
\text { comunicación a través de cualquier medio y tecnología.". (Área Moreira, } \\
\text { 2008). }\end{array}$ & \begin{tabular}{lrr}
\multicolumn{2}{c}{ Catedrático de } & universidad \\
del área de & Didáctica y \\
Organización & & Escolar. \\
Universidad de & La & Laguna. \\
España. & & \\
\end{tabular} & & & $\mathrm{X}$ \\
\hline (Uribe Tirado, 2009) & $\begin{array}{l}\text { "El proceso de enseñanza-aprendizaje que busca que un individuo y } \\
\text { colectivo, gracias al acompañamiento profesional y de una institución } \\
\text { educativa o bibliotecológica, empleando diferentes estrategias didácticas } \\
\text { y ambientes de aprendizaje (modalidad presencial, «virtual» o mixta - } \\
\text { blend learning-), alcance las competencias (conocimientos, habilidades y } \\
\text { actitudes) en lo informático, comunicativo e informativo, que le } \\
\text { permitan, tras identificar sus necesidades de información, y utilizando } \\
\text { diferentes formatos, medios y recursos físicos, electrónicos o digitales, } \\
\text { poder localizar, seleccionar, recuperar, organizar, evaluar, producir, } \\
\text { compartir y divulgar (comportamiento informacional) en forma adecuada } \\
\text { y eficiente esa información, con una posición crítica y ética, a partir de } \\
\text { sus potencialidades (cognoscitivas, prácticas y afectivas) y } \\
\text { conocimientos previos (otras alfabetizaciones), y lograr una interacción } \\
\text { apropiada con otros individuos y colectivos (práctica cultural-inclusión } \\
\text { social), según los diferentes papeles y contextos que asume (niveles } \\
\text { educativos, investigación, desempeño laboral o profesional), para } \\
\text { finalmente con todo ese proceso, alcanzar y compartir nuevos } \\
\text { conocimientos y tener las bases de un aprendizaje permanente para }\end{array}$ & $\begin{array}{l}\text { Máster en Ingeniería. } \\
\text { Escuela Interamericana de } \\
\text { Bibliotecología. Universidad de } \\
\text { Antioquia, Colombia. }\end{array}$ & & & $\mathrm{X}$ \\
\hline
\end{tabular}




\begin{tabular}{|c|c|c|c|c|c|}
\hline Autor (es) & \multirow{2}{*}{\multicolumn{2}{|c|}{ Datos sobre el autor }} & \multirow[t]{2}{*}{\begin{tabular}{|c|} 
Bawden, \\
D.
\end{tabular}} & \multirow[t]{2}{*}{\begin{tabular}{|c|} 
Uribe, \\
A.
\end{tabular}} & \multirow[t]{2}{*}{$\begin{array}{l}\text { Rodrí- } \\
\text { guez, } 1 .\end{array}$} \\
\hline & & & & & \\
\hline $\begin{array}{l}\text { (Martínez Aldanondo, } \\
\text { 2009) }\end{array}$ & $\begin{array}{l}\text { "El aprendizaje es un proceso activo, de construcción de } \\
\text { conocimiento, y no un proceso pasivo de acumulación de información. } \\
\text { La alfabetización informacional deberá considerarse como una estrategia } \\
\text { de la institución universitaria. Se educará al estudiante para formación } \\
\text { permanente: Reconocer las propias necesidades informativas, Localizar } \\
\text { la información y evaluar su calidad, Estructurar, sintetizar y entender } \\
\text { para recuperarla cuando la necesite, Reutilizarla de forma eficaz y ética, } \\
\text { Aplicarla para crear y comunicar nuevo conocimiento". (Martínez } \\
\text { Aldanondo, 2009). }\end{array}$ & $\begin{array}{l}\quad \text { Gerente de Gestión del } \\
\text { Conocimiento del Proyecto } \\
\text { Catenaria. España. }\end{array}$ & & & $\mathrm{X}$ \\
\hline (Campal García, 2010) & $\begin{array}{l}\text { "ALFIN, por tanto, es una competencia básica para el manejo de la } \\
\text { información... es necesario apuntar que en la actual sociedad de la sobre } \\
\text { información, el ciudadano interactúa con personas y máquinas } \\
\text { intercambiando datos e información en cualquier formato. Las } \\
\text { habilidades de lecto-escritura (alfabetización tradicional) no son } \\
\text { suficientes. Hay necesidad de otras nuevas alfabetizaciones: - } \\
\text { Alfabetización múltiple. - Alfabetización continua o aprendizaje } \\
\text { permanente". (Campal García, 2010). }\end{array}$ & $\begin{array}{l}\text { Profesora asociada. Facultad } \\
\text { de Traducción y } \\
\text { Documentación. Universidad de } \\
\text { Salamanca. }\end{array}$ & & & $\mathrm{X}$ \\
\hline (Flores Noriega, 2011) & $\begin{array}{l}\text { "Alfabetización informacional significa crear las condiciones para } \\
\text { que un individuo adquiera un nivel de competencia óptima, para que } \\
\text { pueda conducirse de manera autónoma y responsable en el uso de la } \\
\text { información, no sólo en el ambiente académico sino también en el } \\
\text { laboral". (Flores Noriega, 2011). }\end{array}$ & $\begin{array}{l}\text { Licenciada en } \\
\text { Bibliotecología y Ciencias de la } \\
\text { Información por la Universidad } \\
\text { Nacional Mayor de San Marcos. }\end{array}$ & & & $X$ \\
\hline $\begin{array}{l}\text { (Meneses Placeres y Pinto } \\
\text { Molina, 2011) }\end{array}$ & $\begin{array}{l}\text { "La ALFIN puede ser considerada como una actividad docente en } \\
\text { tanto depende de varios factores que desencadenan un proceso de } \\
\text { aprendizaje. Es válido recordar que la ALFIN es un modo de aprender, } \\
\text { por tanto existe la persona a alfabetizar y el encargado de llevar esto a } \\
\text { cabo, a partir de la utilización de métodos, medios y procedimientos que } \\
\text { estimularán o frenarán la acción, con unos objetivos previamente } \\
\text { identificados". (Meneses Placeres y Pinto Molina, 2011). } \\
\text { Estas autoras se apoyan en los criterios de (Kuhlthau, } 1987 \text { citado en } \\
\text { Loertscher). }\end{array}$ & $\begin{array}{l}\text { Meneses Placeres - Dr. }{ }^{\mathrm{a}} \text { en } \\
\text { Ciencias de la Información. } \\
\text { Universidad Central de las } \\
\text { Villas. } \\
\quad \text { Pinto Molina - Catedrática } \\
\text { de Documentación. Facultad de } \\
\text { Biblioteconomía } \\
\text { Documentación. Universidad de } \\
\text { Granada. España }\end{array}$ & & & $\mathrm{X}$ \\
\hline (Campal García, 2011) & $\begin{array}{l}\text { "En el marco de la formación en ALFIN 2.0, pasan a un primer orden } \\
\text { la capacitación en las siguientes áreas: } \bullet \text { Sentido crítico y habilidades de } \\
\text { evaluación de recursos e información en cualquier medio. } \bullet \text { Valoración } \\
\text { de la recomendación por parte de los amigos y colegas: delicious, }\end{array}$ & $\begin{array}{l}\text { Profesora asociada. Facultad } \\
\text { de Traducción y } \\
\text { Documentación. Universidad de } \\
\text { Salamanca. }\end{array}$ & & & $\mathrm{X}$ \\
\hline
\end{tabular}




\begin{tabular}{|c|c|c|c|c|c|}
\hline Autor (es) & Definición & Datos sobre el autor & $\begin{array}{c}\text { Bawden, } \\
\text { D. }\end{array}$ & $\begin{array}{c}\text { Uribe, } \\
\text { A. }\end{array}$ & $\begin{array}{l}\text { Rodrí- } \\
\text { guez, l. }\end{array}$ \\
\hline & $\begin{array}{l}\text { Amazon, comentarios, valoraciones, etc. } \bullet \text { Contenidos generados por los } \\
\text { usuarios (la inteligencia de las muchedumbres). } \bullet \text { Copyright, derechos de } \\
\text { autor, Open Access, creative commons, Copyleft, Plagio, Saber citar, } \\
\text { etc". (Campal García, 2011). }\end{array}$ & & & & \\
\hline (Rodríguez Castilla, 2012) & $\begin{array}{l}\text { "Proceso de aprendizaje continuo para desarrollar en los individuos } \\
\text { habilidades con el uso de la información, ya sea en formato impreso o } \\
\text { digital; resaltando como habilidades fundamentales la definición de } \\
\text { necesidades de información, su localización, evaluación, organización y } \\
\text { análisis crítico, que todas en su conjunto, tributen a la generación de } \\
\text { nuevos conocimientos, que al comunicarlos de manera ética, se convierta } \\
\text { en nueva información". (Rodríguez Castilla, 2012). }\end{array}$ & $\begin{array}{l}\text { Licenciada en } \text { Información } \\
\text { Científico-Técnica } \\
\text { Bibliotecología. Máster en } \\
\text { Gestión de Proyectos } \\
\text { Informáticos. Profesora CREA- } \\
\text { CUJAE. Cuba. Aspirante a } \\
\text { doctora en el Doctorado Tutelar } \\
\text { Colaborativo de Ciencias } \\
\text { Pedagógicas de la CUJAE. }\end{array}$ & & & $\mathrm{X}$ \\
\hline $\begin{array}{l}\text { (IFLA/UNESCO/IFAP, } \\
\text { 2012) }\end{array}$ & $\begin{array}{l}\text { "Se define a la AMI* como una combinación de conocimientos, } \\
\text { actitudes, competencias y prácticas necesarias para acceder, analizar, } \\
\text { evaluar, usar, producir y comunicar información y conocimiento de } \\
\text { maneras creativas, legales y éticas que respeten los derechos humanos. } \\
\text { Los individuos alfabetizados en información y medios pueden usar } \\
\text { diversos medios, fuentes de información y canales en su vida privada, } \\
\text { profesional y pública. Saben qué información necesitan, cuándo y para } \\
\text { qué, y dónde obtenerla. Entienden quién ha credo la información y por } \\
\text { qué, así como los roles, responsabilidades y funciones de los medios, los } \\
\text { proveedores de información y las instituciones de la memoria. Pueden } \\
\text { analizar información, mensajes, creencias y valores transmitidos a través } \\
\text { de los medios y de toda clase de productores de contenidos, y pueden } \\
\text { comparar y validar la información que han hallado y procesado en base a } \\
\text { criterios genéricos, personales y basados en sus contextos. Las } \\
\text { competencias en AMI se extienden así más allá de las tecnologías de } \\
\text { información y comunicación, para incluir las habilidades del aprendizaje, } \\
\text { el pensamiento crítico y la interpretación a través de los límites } \\
\text { profesionales, educativos y sociales. La AMI se dirige a todos los tipos } \\
\text { de medios (orales, impresos, analógicos y digitales) y a todas las formas } \\
\text { de formatos y soportes". (Unesco et al., 2012). } \\
\text { Declaración de Moscú sobre Alfabetización Mediática e } \\
\text { Informacional. } \\
\text { Aprobada por } 130 \text { participantes de } 40 \text { países. } \\
\text { *Alfabetización Mediática e Informacional. }\end{array}$ & $\begin{array}{l}\text { International Federation of } \\
\text { Library Associations and } \\
\text { Institutions- IFLA - Federación } \\
\text { Internacional de las } \\
\text { Asociaciones y de las } \\
\text { Instituciones de la Biblioteca. } \\
\text { UNESCO- La Organización } \\
\text { de las Naciones Unidas para la } \\
\text { Educación, la Ciencia y la } \\
\text { Cultura, es un organismo } \\
\text { especializado de las Naciones } \\
\text { Unidas. } \\
\text { IFAP-UNESCO'S } \\
\text { Information for All Programme. } \\
\text { Programa de Información para } \\
\text { todos. }\end{array}$ & & & $\mathrm{X}$ \\
\hline
\end{tabular}

Tabla II. Lista de definiciones analizadas. 